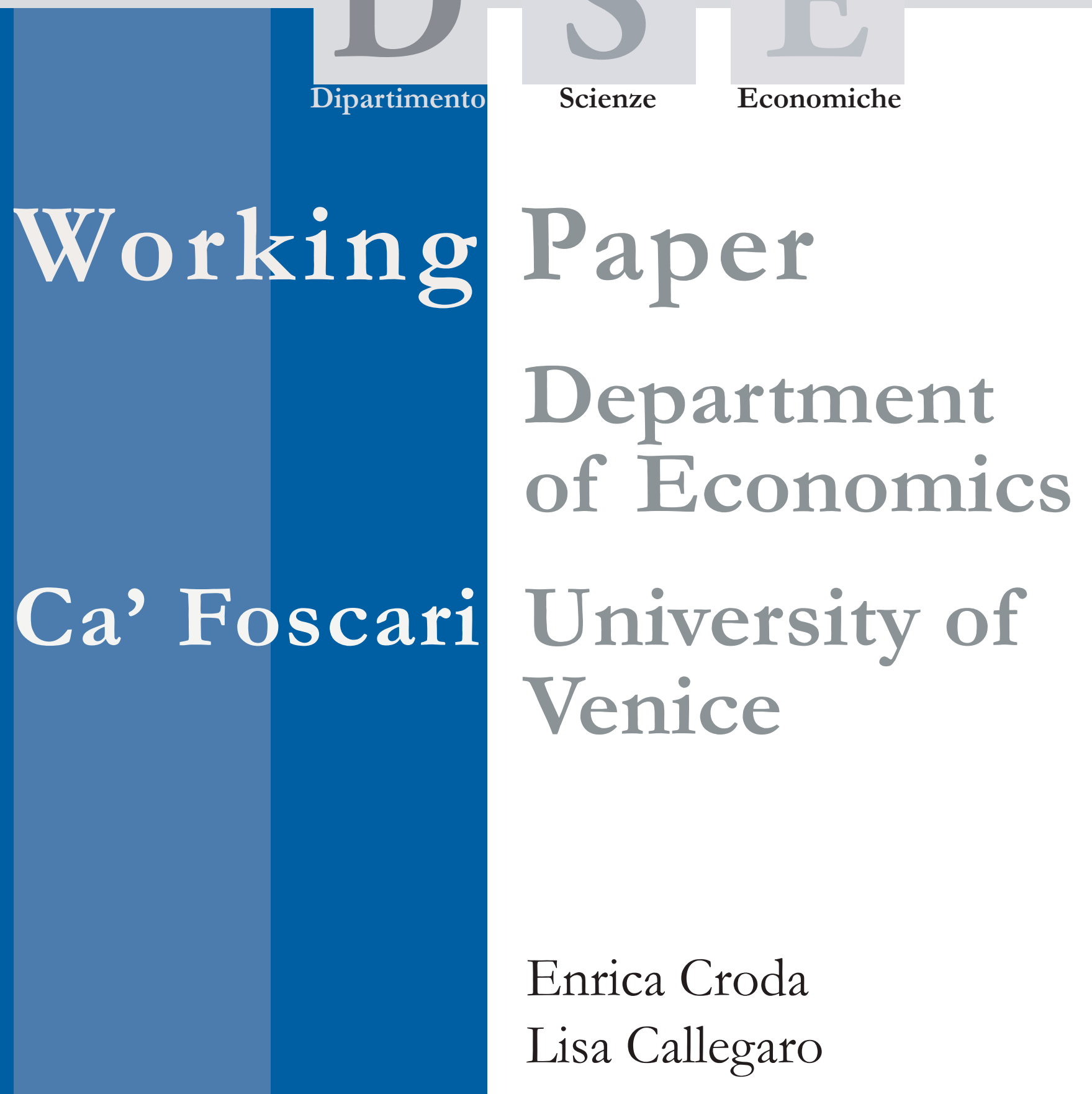




\title{
The Employment and Pensions Module in SHARE Wave 1
}

\author{
Enrica Croda \\ Ca' Foscari University of Venice \\ Lisa Callegaro \\ Ca' Foscari University of Venice
}

October 2006

\begin{abstract}
This paper documents the Employment and Pensions module in the first wave of the Survey of Health, Ageing and Retirement in Europe (SHARE). This is the first survey in Europe that collects extensive cross-national interdisciplinary data on different aspects of the life of the elderly, ranging from health conditions to economic status. The Employment and Pensions module is constructed to elicit information on labor force participation, earnings and other incomes such as pensions and benefits. We show both the structure of the module and selected preliminary results.
\end{abstract}

\section{Keywords}

Aging, employment, pensions, household survey, cross-national research, Europe, SHARE

\section{JEL Codes}

$\mathrm{J} 14, \mathrm{~J} 26, \mathrm{C} 81$

Address for correspondence:

Lisa Callegaro

Phone: $(++39) 0412349105$

Fax: (++39) 0412349176

e-mail: lcallegaro@unive.it

Enrica Croda

Phone: $(++39) 0412349234$

Fax: (++39) 0412349176

e-mail: enrica.croda@unive.it

Department of Economics

Ca' Foscari University of Venice

This Working Paper is published under the auspices of the Department of Economics of the Ca' Foscari University of Venice. Opinions expressed herein are those of the authors and not those of the Department. The Working Paper series is designed to divulge preliminary or incomplete work, circulated to favour discussion and comments. Citation of this paper should consider its provisional character.

The Working Paper Series is availble only on line www.dse.unive. it/pubblicazion For editorial correspondence, please contact: wp.dse@unive.it
Department of Economics

Ca' Foscari University of Venice

Cannaregio 873, Fondamenta San Giobbe

30121 Venice Italy

Fax: ++390412349210 


\section{The Employment and Pensions Module in SHARE Wave 1 * ENRICA CRODA AND LISA CALLEGARO \\ October 2006}

\section{INTRODUCTION}

Population aging is one of the greatest social and economic challenges of the $21^{\text {st }}$ century. Europe is aging faster than other parts of the world: It has the highest proportion of persons aged 65 or over (about 15\%) among the world's regions, with Italy having the highest proportion of persons aged 65 or over (18\% in 2000). In Europe, the old-age dependency ratio, namely the ratio of persons aged over 65 as a percentage of the working age population $20-64$, is expected to increase from about $27 \%$ in 2000 to $53 \%$ in 2050 . $^{1}$ This increase of the dependency ratio in itself places a heavy financial burden on society through pay-as-you-go financed pension, health and longterm care systems. There are other pressures on the social security and welfare systems as well. Older workers are more likely to be in some kind of disability programs. Moreover, Europeans have been retiring much earlier than inhabitants of other developed countries: for instance, in Belgium only a quarter of all males are still in the labor force at age 55-64, compared to three quarters in Japan.

This typically European combination of an aging population and retirement at ever earlier ages with relatively generous benefits puts very severe strains on our capacity to care for the elderly in the future. Thus, everything else equal, aging places a much higher burden on the sustainability of income maintenance systems in Europe than elsewhere in the world, challenging European public policy - pension policy, health care policy, labour market policy.

\footnotetext{
* The SHARE data collection has been primarily funded by the European Commission through the 5th framework programme (project QLK6-CT-2001-00360 in the thematic programme Quality of Life). Additional funding came from the US National Institute on Aging (U01 AG09740-13S2, P01 AG005842, P01 AG08291, P30 AG12815, Y1-AG-4553-01 and OGHA 04-064). Data collection in Austria (through the Austrian Science Fund, FWF), Belgium (through the Belgian Science Policy Office) and Switzerland (through BBW/OFES/UFES) was nationally funded. We thank Agar Brugiavini, leader of the Employment and Pensions Working Group, and Roberta Rainato for helpful comments.

${ }^{1}$ United Nations (2001).
} 
In order to be able to face the challenges posed by population aging in Europe it is crucial to understand the complex interaction between social, economic and health factors that affect the well-being of the elderly and how they are affected by national policies. However, this understanding requires the availability of multidisciplinary data on the elderly. Whereas in the US this kind of data has been available since the early $1990 \mathrm{~s},{ }^{2}$ up to a few months ago, Europe was ill equipped for this task. Some EU member states have been collecting data on some specific discipline, but Europe was missing interdisciplinary data sets, and especially interdisciplinary data sets which could have been comparable across countries and could become longitudinal over time.

SHARE, the Survey of Health, Ageing and Retirement in Europe has been designed to fill this gap. SHARE is modelled after the US Health and Retirement Survey (HRS) and the English Longitudinal Study of Ageing (ELSA). However, while ELSA and HRS only collect data in a single country, SHARE adds to this an additional dimension: It is the first European survey that collects extensive cross-national interdisciplinary data on socioeconomic variables, health status, family networks of the older population. One of the strength of SHARE is indeed the fact that it asks the same questions in all the countries that are part of the project.

So far, SHARE has collected in 2004 a first baseline wave of data on some 29,000 individuals aged 50 and over, including their spouses, irrespective of age, living in 20,000 households in eleven countries ranging from Scandinavia (Sweden, Denmark), Western and Central Europe (France, Belgium, The Netherlands, Germany, Switzerland, Austria) to the Mediterranean (Spain, Italy, Greece). Additional data have been collected in Israel in $2006^{3}$

\footnotetext{
${ }^{2}$ The Health and Retirement Survey project started collecting this kind of longitudinal data in 1992.

${ }^{3}$ In each participating country, probability samples where drawn. When appropriately weighted, the SHARE sample is representative of the target population. Sample sizes and gender composition of the available sample by country are shown in Table A1 in Appendix A. Throughout the paper, the following standard symbols are used to denote the different countries: SE for Sweden, DK for Denmark, DE for Germany, NL for the Netherlands, BE for Belgium, FR for France, CH for Switzerland, AT for Austria, ES for Spain, IT for Italy, and GR for Greece.
} 
The goal of this paper is to document the Employment and Pensions module in the first wave of the SHARE questionnaire. This module was constructed to elicit information on labor force participation, earnings and other incomes such as pensions and benefits. In addition to providing a discussion of the questions asked, we present some preliminary analysis of the available data, in order to guide the reader through the module and to demonstrate its value. A detailed description of the SHARE project is beyond the scope of this paper. The interested reader is referred to the project's web-site, www.SHARE-project.org, and the documentation therein.

The remainder of the paper is organized as follows. The next section provides a brief overview of the whole questionnaire. Section 3 focuses on the Employment and Pensions module, describing in detail the questions asked and presenting selected preliminary results based on the data collected so far. Finally, section 4 concludes.

\section{OVERVIEW OF THE SHARE QUESTIONNAIRE}

The SHARE questionnaire contains questions about demographic variables (the usual suspects: age, gender, marital status, education, household size...), health variables (e.g. self-reported health status, physical functioning, cognitive functioning, physical measures such as grip strength and walking speed, health behaviour, use of health care facilities), psychological variables (e.g. psychological health, well-being, life satisfaction), economic variables (e.g. current work activity, job characteristics, job flexibility, opportunities to work past retirement age, employment history, pension entitlements, sources and composition of current income, wealth and consumption, housing, education), social support variables (e.g. assistance within families, transfers of income and assets, time help, social networks, volunteer activities).

The questionnaire is composed by face-to-face computer-aided personal interviews (CAPI), plus a self-completion drop-off part with questions that command more privacy. The survey instrument is first written 
in English and then translated into the specific language of each country or region within country (Switzerland has a German, a French and an Italian version; Belgium a Dutch and a French one). ${ }^{4}$

Eligible respondents in the first wave are all household members aged 50 and over, plus their spouses, independent of age. Some parts of the questionnaire need only be answered by one respondent in a household or couple, respectively. For instance, questions on housing and housing finances should be answered by the household member who is most knowledgeable in housing matters ("housing respondent") and questions about finances need to be answered by one person in each financial unit (the "financial respondent"), where a financial unit can be either a single person or a couple. In the case of couple, the "financial respondent" should be the partner who is most knowledgeable about finances. However, if the members of a couple keep their finances completely separate, they are treated as separate financial units and each of them answer their own questions on finances.

\subsection{Description of modules}

The questionnaire is divided into several sections, each focusing on a specific discipline. In particular, it is composed by the following modules.

1. Coverscreen $(\mathrm{CV})$

2. Demographics (DN)

3. Physical Health (PH)

4. Cognitive function $(\mathrm{CF})$

5. Mental Health $(\mathrm{MH})$

6. Health Care (HC)

7. Employment and Pensions (EP)

8. Grip Strength (GS)

9. Walking Speed (WS)

10. Children $(\mathrm{CH})$

11. Social Support (SP)

${ }^{4}$ Israel has three different versions of the questionnaire: a Hebrew, an Arabic, and a Russian version. 
12. Financial Transfers (FT)

13. Housing $(\mathrm{HO})$

14. Household Income (HH)

15. Consumption $(\mathrm{CO})$

16. Assets (AS)

17. Expectations (EX)

18. Interviewer Observations (IV)

The questionnaire starts with a "coverscreen" which collects basic demographic information about everyone who currently lives in the contacted household (name, gender, birth year and month, marital status). This section is completed only by one person in each household, the socalled "informant", and is meant to establish which household member is eligible for an interview and who is going to be the housing, financial, and family respondent. The Demographics module collects details about each respondent's marital status, country of birth, education, and occupation. It also collects selected information about the parents of a respondent such as last occupation, health status, and frequency of contact. SHARE asks very detailed information regarding the health status of respondents. The Physical Health module asks about several aspects of people's health: selfreported general health, longstanding illness or disability, eyesight and hearing, specific diagnoses and symptoms, pain and difficulties with a range of activities of daily living. Information on potentially risky health behaviours such as smoking, alcohol use, and also about physical activities is collected in the Behavioural Risks module. The Cognitive Functions module contains subjective and objective measures of four aspects of the respondent's cognitive functioning: literacy, numeracy, memory, and verbal fluency. The Mental Health module asks how respondents view their own life and collects information about emotional problems. The Health Care module asks about recent doctor visits and hospital stays, and about the respondent's level of health insurance. The Employment and Pensions module, focus of the present paper, collects information about respondents' current work activities, their income from work and other sources, and any 
current or past pensions that they may be entitled to. Respondents who are retired and are receiving a pension, are asked about the number and type of pensions they receive and how much they receive. Two kinds of physical measurements, one involving recording the respondent's maximum handgrip strength with a dynamometer, and the other asking the respondent to walk a certain distance and measuring the time it takes for the respondent to complete this activity, are collected in the Grip Strength and in the Walking Speed modules, respectively. ${ }^{5}$ Next, the Children module collects information about the respondents' children. It is followed by the Social Support module asking about any help respondents might receive from family and other people not living in the household or might give to others. Questions on most kinds of help received by members of a couple are asked only to the family respondent. The Financial Transfers module asks the "financial respondent" about any regular financial transfers and payments respondents may have given or received from non-household members and about inheritances. Information about the respondents' current housing situation, including the size and quality of the accommodation, is collected in the Housing module. Questions in this module are asked only to one person per household, regardless of how many people are eligible for the interview. Owners are asked about the value of their property and, depending on their tenure, "housing respondents" are asked about mortgages and rent payments. The Household Income module collects summary measures of the household income from various sources. The Consumption module investigates different types of household expenditures, e.g. on food, fuel, electricity, and telephone. It is answered by the "housing" respondent. The Assets module asks about the amount of financial and non-financial assets held in several forms and income from these assets. This section should be completed by the "financial respondent". The Expectations module explores people's expectations, the level of certainty they feel about the future, and how they value risk and make financial decisions within their household. Finally, the questionnaire

\footnotetext{
${ }^{5}$ Only persons aged $65+$ are asked to perform the latter test.
} 
ends with some questions for the interviewers on the interviewing experience from their point of view.

The current version of the questionnaire is available at www.SHAREproject.org.

\section{The EMPloyment AND Pensions (EP) Module}

The Employment and Pensions (EP) module is asked to all respondents. The questions asked are reported in Appendix B. The routing of these questions depends on the labor force participation status of a respondent, as defined in the first five questions, and is shown in a flowchart in Appendixes C.1 through C.4. For clarity, the flow-chart is displayed in four parts, the first part focuses on labor force participation (Appendix C.1), the second part on the current job situation (Appendix C.2), the third part on the past job (Appendix C.3), and finally the fourth and last part organizes the last year income and future benefits entitlements questions (Appendix C.4). ${ }^{6}$

\section{1. Labor force participation status}

The EP module begins with a set of questions, EP005 through EP006, meant to define as accurately as possible the labor force participation status of a respondent. EP005 asks individuals to self-report their current status according to a set of mutually exclusive categories: retired, employed or self-employed (including working for family business), unemployed (and looking for work), permanently sick or disabled, homemaker or "other". The interviewer is instructed to let respondents select the category in which they fit, and advise them only if they are in doubt. ${ }^{7}$ Basically, EP005 aims at

\footnotetext{
${ }^{6}$ Before converging to the final version (version 10), the questionnaire went through several revisions. The numbering of the questions in the final version is not necessarily sequential because it follows the order in which they were originally designed, even some of them have been moved back and forth during the revisions.

${ }^{7}$ QxQs are provided to interviewers on this question. The following suggestions are given: "Retired" refers to respondents no longer engaged in paid work, but working in the past; "employed or selfemployed" is meant to capture both paid work, or unpaid work, including also working for family business without an employment contract; "unemployed" refers to individuals who are laid out or out of work, including short term unemployed; "permanently sick or disabled" includes partially disabled or partially invalid; "homemaker" includes looking after home or family with no payment. "Other" could be a rentier etc.
} 
capturing how respondents view themselves, distinguishing between those who are retired from a previous job, those who are still attached to the labor force, either as employed or unemployed, and those who are out of the labor force.

Table 1. Prevalence of Self-reported Labor Market Status

\begin{tabular}{lrc}
\hline & $\mathrm{N}$ & $\begin{array}{c}\text { Prevalence } \\
(\%)\end{array}$ \\
\hline Retired & 13,496 & 47.59 \\
$\begin{array}{l}\text { Employed } \\
\text { or Self-Employed }\end{array}$ & 8,087 & 28.52 \\
$\begin{array}{l}\text { Unemployed } \\
\text { Permanently sick }\end{array}$ & 854 & 3.01 \\
or disabled & 865 & 3.05 \\
Homemaker & 4,379 & 15.44 \\
Other & 675 & 2.38 \\
\hline
\end{tabular}

Source: Authors' calculations using SHARE Release February 27, 2006. Based on a sample of 28,356 individual 50+ respondents who reported their current situation in EP005. Percentage values.

Table 1 shows the prevalence of self-reported states in the overall sample. $^{8}$ Not surprisingly, work and retirement are the two prevalent economic activities in SHARE: about 3 out of 10 respondents are employed and about one out of two is retired (28.52\% and $47.59 \%$, respectively). A relevant fraction of the whole sample report being a homemaker $(15.44 \%) .{ }^{9}$

Disaggregating by gender, Figure 1 highlights how men classify themselves mostly as retired $(54.33 \%)$ or employed $(36.48 \%)$, while women distribute themselves mostly among three groups: retired (43.75\%),

Figure 1. Self-Reported Economic Activity by Gender

\footnotetext{
${ }^{8}$ All descriptive statistics in this and the following tables and graphs are weighted.

${ }^{9}$ If respondents answered "Other", they were then asked in EP200 to specify what they meant: 667 respondents provided such a description. About $90 \%$ gave answers that could be recoded into the EP005 categories 1-5, the remaining $10 \%$ answered something like "rentier", "living of own property", "student", "doing voluntary work".
} 


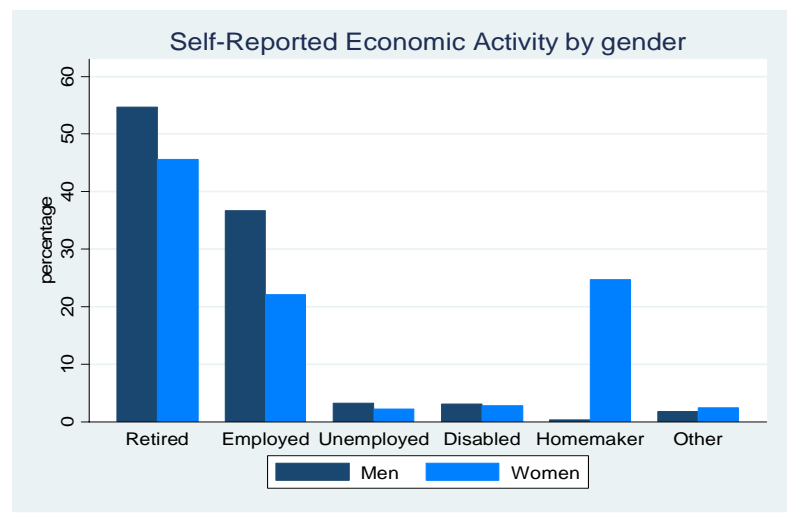

homemakers (25.22\%) and employed (23.05\%), with the prevalence of homemaking activities being higher than the prevalence of employment.

Disaggregating further across countries is very informative, because it shows the high heterogeneity existing across Europe. ${ }^{10}$ Figure 2 displays the three most common self reported states for each gender by country. A

Figure 2. Self-Reported Economic Activity by Gender and Country (Three most prevalent activities by gender)
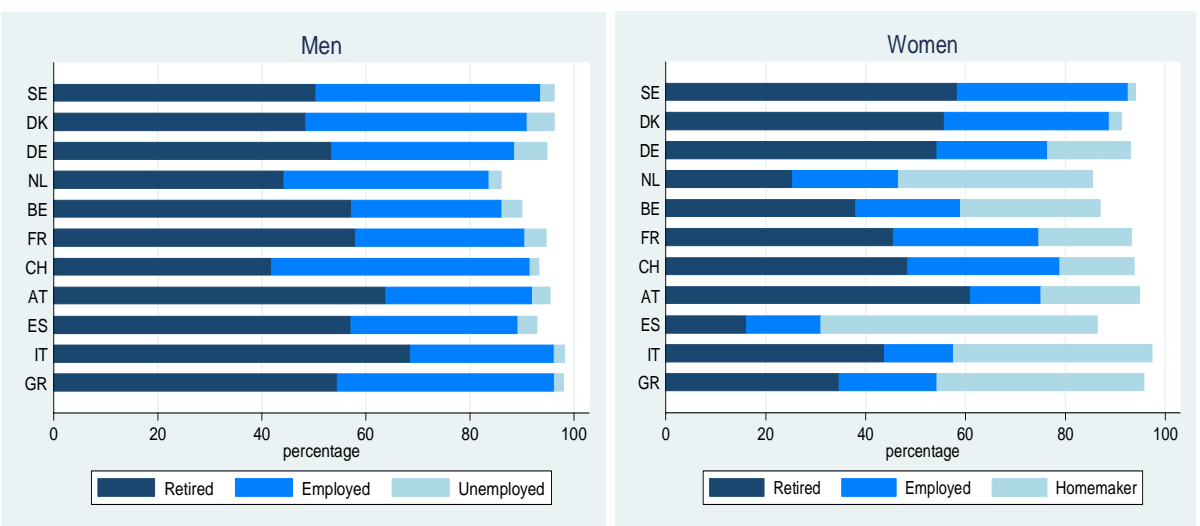

A striking North-South gradient emerges in the fraction of women reporting themselves as homemakers, possibly due to social norms and institutional differences: Very few women in the Nordic countries report themselves as homemakers (1.54\% in Sweden and $2.49 \%$ in Denmark). In contrast, a large fraction of women in the Mediterranean countries do so: $55.38 \%$ in Spain,

\footnotetext{
${ }^{10}$ Table A2 in Appendix A provides the (weighted) average distribution of all the six categories by country and gender.
} 
and $41.39 \%$ and $39.72 \%$ in Greece and Italy, respectively. There is a clear country-pattern in the distribution of activities among men as well, with the proportion of employed respondents ranging between $27-28 \%$ in Italy and Austria to 43 and $49 \%$ in Sweden and Switzerland, respectively, while retired individuals range between $42 \%$ in Switzerland to over $60 \%$ in Austria (64\%) and Italy (68.56\%).

Figure 3: Self-Reported Economic Activity by Age

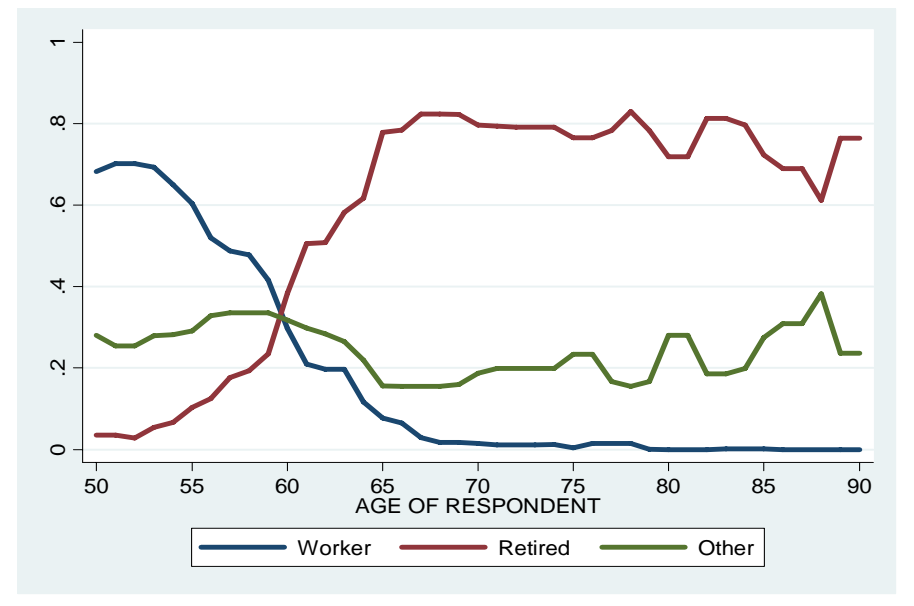

Dynamic considerations will be possible only when further waves of SHARE will be collected. At this point we can only rely on the crosssectional nature of the dataset and provide a snapshot of economic activity of older Europeans at different ages. Figure 3 shows the distribution of selfreported economic activity of individuals of different ages focusing on respondents self-reporting as employed or retired, and grouping all the other answers into "other". ${ }^{11}$ As expected the proportion of respondents reporting themselves as employed decreases with age, and the proportion of those reporting themselves as retired increases with age, with employment being the prevalent state before age 60 , and retirement prevailing afterwards.

In theoretical economic models, retirement is usually described as a direct transition from a state of full employment to a state in which

\footnotetext{
${ }^{11}$ This graph is based on the answers given to EP005 by both male and female respondents of different ages. Age profiles are given by single year-of-age groups, but they have been previously smoothed to remove most of the sampling variability that is observed in the raw data.
} 
individuals are completely inactive and most of their resources consist of pension benefits. But, over the last decades, this description has become less and less realistic, particularly in Europe, where, mostly in response to labor market rigidities, many countries have allowed and sometimes even encouraged various forms of early exit from the labor force before entering normal retirement. The main tools for doing so have been unemployment insurance, extended access to sickness or disability leaves, or the development of specific pre-retirement schemes. As a consequence, on one hand, a wedge has been created between employment and retirement, and the frontiers of these two states have been moving away from each other. On the other hand, there also exists several situations where these two frontiers overlap instead of moving apart: This happens when retirement is gradual and when there is a period of time during which individuals combine labor income and pension benefits. SHARE has been expressedly designed to capture these patterns and to facilitate the study of transitions to retirement through these different routes. ${ }^{12}$

The quantitative importance of these different routes varies considerably across countries, especially because of institutional differences. ${ }^{13}$ Figure 4 focuses on three states: "unemployed", "permanently sick or disabled" and "retired", and shows the prevalence of these different states across the SHARE countries relying on the answers given to EP005 by respondents of different ages. Countries are organized in three groups: the Northern countries to the left, the Mid-European/Continental ones in the middle, and the Mediterranean/Southern ones to the right. The top panel displays the distribution of retirees, the middle panel the distribution of disabled, and the bottom panel the distribution of unemployed. ${ }^{14}$

Among the three Northern countries, the lines for the Netherlands show clearly the substitutability that can exist between the two routes of unemployment and disability. The importance of the disability route for the

\footnotetext{
${ }^{12}$ This will be even more evident when SHARE will become longitudinal.

${ }^{13}$ See, for instance, the MISSOC Tables for more details on the different institutional arrangements. See also Blöndal and Scarpetta (1998) and Gruber and Wise (1999, 2004).

${ }^{14}$ The construction of these graphs is based on the procedure described in footnote 11 .
} 
Netherlands is a well-documented aspect of the management of older workers in that country. ${ }^{15}$ Among the Mid-European countries, Switzerland appears to be the country where age at entry into retirement is the oldest, and where, for each age of interest, the fraction of individuals in disability or unemployment is almost always the lowest. The other countries show quite different profiles of final transitions into retirement. The ages at which about $50 \%$ of respondents report themselves as retired are about 58 in Austria, 59.5 in France, and 62 in Germany. Before these ages, the three countries exhibit relatively comparable unemployment or disability rates, with a slight predominance of unemployment. "Pathways" to retirement for Southern countries show less homogeneity. The ages at transition to retirement seem to differ significantly across these countries: the age at which $50 \%$ of the people report themselves as retired is 59 for Italy, 63 for Greece and 65 for Spain. The result that the fraction of respondents reporting themselves as retired does not seem to go above $80 \%$ even at old ages is due to the fact that these graphs include both genders and to the high prevalence of individuals, essentially women, who report themselves as homemakers in these countries. In fact, for homemakers there is basically no notion of transition to retirement. Before this transition to retirement, a variety of patterns emerge for the three countries. Disability is almost nonexistent for Italian and Greek respondents younger than 60. In Italy, it remains so also for respondents older than 60 . In particular, Italy displays low or very low rates for both unemployment and disability, possibly because early retirement at a very young age is widespread.

\footnotetext{
${ }^{15}$ See, for instance Gruber and Wise (1999).
} 
Figure 4. Distribution of Retired, Disabled and Unemployed Individuals in Northern, Mid-European and Southern Countries
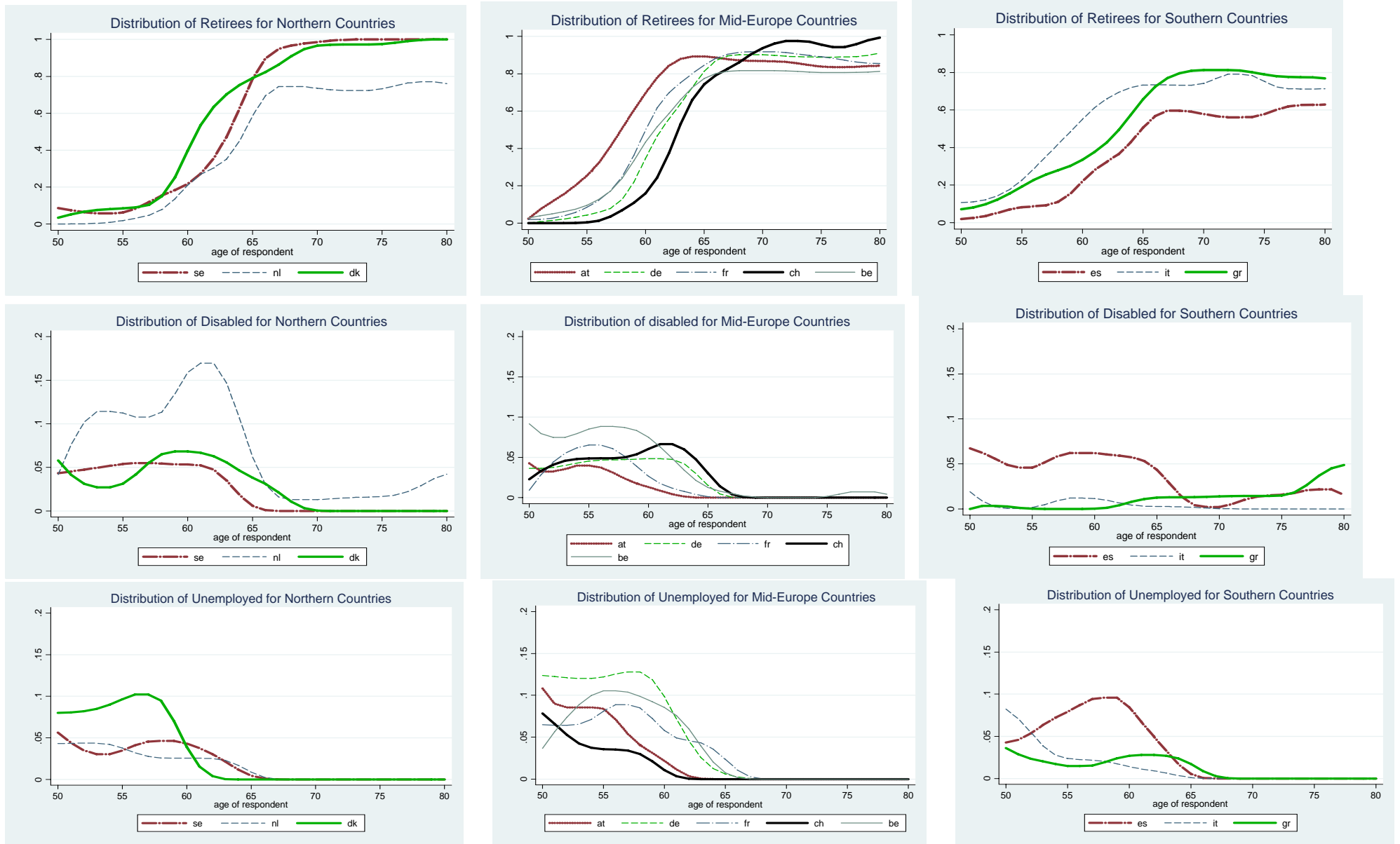
Spain stands out among the Mediterranean countries for having a higher prevalence of unemployment before retirement age, and by showing a large drop in the proportion of unemployed between age 59 and 65 , obviously due to exits into retirement.

Another aspect of the transition between work and retirement is the role played by partial or gradual retirement, situations where an individual simultaneously receives earnings and pension benefits, for example because the transition out of work is gradual. Workers might keep working for the same employer they used to, but work fewer hours, or they may fully retire from a job and take up a new job with a different employer, or become selfemployed.

The mutually exclusive answers to EP005 cannot capture the reality of people who may actually fit in more than one category, such as the retiree who does some hours of work, or even the disabled person who is able to work and does work. Since the interview is done at a specific point in time, it may also happen that the respondent is a seasonal worker who at the time of the interview is not working. In order to define the effective labor market status of an individual, the EP module makes use of a set of additional questions to capture also those individuals who, even though they consider themselves as retired, do some hours of work, or have worked recently. Specifically, in order to define the effective labor market status of an individual we need to rely on the combination of the answers to EP005, EP002, and EP003. As the flowchart in Appendix B.1 shows, respondents who do not report themselves as being employed or self-employed in EP005, are then asked in EP002 whether they nevertheless did any paid work in the last four weeks, even if it was only for a few hours. If they answer negatively to EP002, they are then asked in EP003 whether they are temporarily away from any work, including seasonal work. Hence, we can construct a definition of effectively working to indicate respondents defining themselves either as employed or self-employed according to EP005 (EP005=employed), or have nevertheless done any paid work in the 
last four weeks (EP002=yes), or are temporarily away from seasonal or regular work (EP003=yes).

Table 2. Labor Force Participation: Workers, Retired but Working, Retired

\begin{tabular}{|c|c|c|c|c|c|c|}
\hline & \multicolumn{3}{|c|}{ Men } & \multicolumn{3}{|c|}{ Women } \\
\hline & $\begin{array}{r}\text { Worker } \\
\text { only }\end{array}$ & $\begin{array}{r}\text { Retired } \\
\text { but } \\
\text { working }\end{array}$ & $\begin{array}{r}\text { Retired } \\
\text { only }\end{array}$ & $\begin{array}{r}\text { Worker } \\
\text { only }\end{array}$ & $\begin{array}{r}\text { Retired } \\
\text { but } \\
\text { working }\end{array}$ & $\begin{array}{r}\text { Retired } \\
\text { only }\end{array}$ \\
\hline SE & 65.63 & 4.69 & 29.68 & 58.81 & 4.43 & 36.76 \\
\hline DK & 61.58 & 6.89 & 31.53 & 55.72 & 2.68 & 41.60 \\
\hline $\mathrm{DE}$ & 52.52 & 3.66 & 43.83 & 44.26 & 3.50 & 52.24 \\
\hline $\mathrm{NL}$ & 62.26 & 2.14 & 35.60 & 69.94 & 1.56 & 28.49 \\
\hline $\mathrm{BE}$ & 48.35 & 2.61 & 49.05 & 45.95 & 1.31 & 52.74 \\
\hline FR & 49.70 & 1.33 & 48.97 & 52.75 & 0.77 & 46.49 \\
\hline $\mathrm{CH}$ & 71.93 & 8.38 & 19.69 & 60.91 & 10.50 & 28.59 \\
\hline AT & 40.89 & 4.48 & 54.63 & 27.89 & 8.19 & 63.92 \\
\hline ES & 53.31 & 1.39 & 45.30 & 70.67 & 1.12 & 28.20 \\
\hline IT & 38.50 & 4.65 & 56.86 & 36.46 & 3.18 & 60.36 \\
\hline GR & 57.06 & 10.76 & 32.17 & 40.79 & 12.41 & 46.80 \\
\hline
\end{tabular}

Source: Authors' calculations using SHARE Release February 27, 2006. Based on sample of 50-70 respondents who reported their current situation. Percentage values. Respondents are classified as retired but working if they self-report as retired and they report work activity in the last four weeks or they are temporarily away from any work. All figures are population-weighted.

Table 2 focuses on respondents aged between 50 and 70, who reported being employed or retired in EP005, and uses the answers to these three questions (EP005, EP002 and EP003) to distinguish between people who only work, are "retired but working", or are fully retired, by gender and country. Greece and Switzerland have the highest fraction of pensioners who do some hours of work, both men and women, at least one out of ten, while France and Spain have the lowest: only one out of 100 . Italy and 
Austria have the highest fraction of "retired only". These results provide additional evidence confirming the role of institutional factors in shaping patterns of prevalence for partial retirement. ${ }^{16}$

Finally, to complete the labor market attachment information, EP006 asks to those respondents who reported not being employed according to EP005 (EP005 $\neq$ employed), not having done any paid work in the last four weeks $($ EP002=no), nor being temporarily away from work $($ EP003=no), whether they have ever done paid work. The answer to this question is going to be used later on in the questionnaire to select the group of respondents to whom to ask specific questions on the reasons why they are in a certain status. In combination with EP005, EP002, EP003, EP006 allows a distinction between those respondents who are or have been attached to the labor market in the past (employed, retired, unemployed persons) and those who have never been attached to it. EP006 somehow checks whether there is someone among the disabled, homemakers or "others" who has ever worked. These individuals will be later asked the reason why the stopped working.

\section{3 .2. Current job situation}

Respondents who are effectively working according to our definition above $[($ EP005=employed $)$, or $($ EP002=yes $)$ or $(E P 003=y e s)]$, are next asked the questions on the current job situation. This part of the questionnaire starts with EP007 asking whether respondents have more than one job, and aims at obtaining information on the current main job and, if respondents work at more than one job, on a secondary job. The main job is defined as the most important job, the one the respondent is working most hours for, and in the case in which the respondent works the same number of hours for more than one job, the one the respondent gets more money from. If the respondent has more than one secondary job, the secondary job is defined as the job with

\footnotetext{
${ }^{16}$ The choice of partial retirement may also results from individual-specific determinants. A detailed analysis of individual retirement decisions is beyond the scope of this paper, but will be the focus of future research.
} 
the most working hours. Respondents who are currently working are first asked a set of questions on their main job, and afterwards on the secondary job, if this applies.

Question EP009 asks respondents whether they work as employee, civil servants, or self-employed. ${ }^{17}$ After EP009, the module asks detailed questions (EP010 through EP024) about the current job: the year in which the respondent started working at this job, the length of the contract, the contracted hours of work, and the hours and months effectively worked, the job title, the qualifications needed and the sector of activity, ${ }^{18}$ and the level of responsibility at work (measured as number of people supervised by the respondent). In the case of the main job, these questions are followed by a set of sociological questions (EP025 through EP035) inquiring about quality of employment by asking how respondents feel about different aspects of their job, such as the degree of job satisfaction, whether the job is physically demanding, the level of time pressure, the degree of freedom in doing their job, opportunities to develop new skills, prospects for job advancement, the level of job security, whether there is adequate support in difficult situations, and the recognition at work. For each of these questions, respondents are given four symmetrical options: strongly agree, agree, disagree and strongly disagree.

Poor quality of work has been found in the literature to be correlated with early retirement and with poor health. One measure of quality of work that has recently received special attention in the literature is based on the so-called effort-reward imbalance model, according to which an imbalance between high effort spent in a job and low rewards received in return adversely affect one's health. ${ }^{19}$ Combining the answers to EP025 through EP035 allows us to construct the effort-reward imbalance index proposed in

\footnotetext{
${ }^{17}$ This question is important because it is used together with EP019 (asking to employees whether they are employed in the public sector) for the routing of the questionnaire so that the questions asked are targeted to the type of job.

${ }^{18}$ The questions regarding the job title, the qualifications needed and the sector of activity are openended questions.

${ }^{19}$ See, for instance, Siegrist, et al. (2006) for more details. The reward is measured in terms of money, esteem, career prospects, and job security.
} 
Siegrist, et al. (2006) and use it in Figure 5 as a measure of poor quality of work.

Figure 5. Poor Quality of Work by Gender, Country and Age Classes
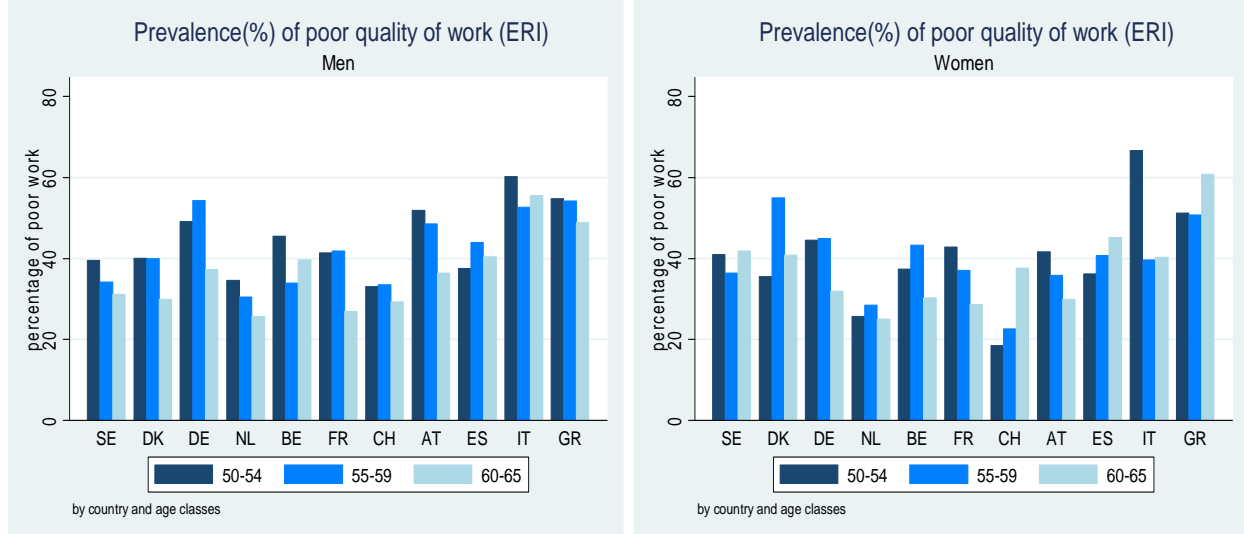

Figure 5 shows the prevalence of poor quality of work for workers 50-65 highlighting the existence of a North-South gradient along this dimension as well. Compared to the Mediterranean countries, a larger fraction of older workers in the Nordic countries appears to be satisfied with the quality of their work-environment. ${ }^{20}$

After these sociological questions, respondents who are not retired, are asked whether they look forward to retire as early as they can, and if they are afraid that their health will limit their ability to work before the regular retirement age.

The current job section ends with a set of questions regarding current income. Two different sets of questions are asked to employee on the one hand, and to the self-employed on the other hand, in accordance with the different nature of these types of jobs.

Employees are asked EP038, EP039, EP041, EP041m, EP214, EP201, EP201m in the order listed. In order to get an updated picture of the current income, EP ask for the amount received in the last payment (EP041). EP also asks how often the person gets paid ("periodicity" - EP038). The

\footnotetext{
${ }^{20}$ Workers here are defined as respondents effectively working: [(EP005=employed $)$, or $($ EP002=yes $)$ or $($ EP003=yes $)]$.
} 
amount question asks how much was the last payment before any deduction for tax, national insurance, or pension and health contributions, union dues, and so on. The module then asks in question EP214 whether this amount includes additional payments and bonuses (such as $13^{\text {th }}$ month, or $14^{\text {th }}$ month payments). If this is the case, question EP201 then asks for the amount of such an additional payment. Everywhere in EP, as well as everywhere else in the questionnaire, amount questions are asked first in local currency. In the euro-countries, if respondents say that they do not know the amount or they refuse to answer to the local currency question, they are next asked for the amount in the pre-euro currency. ${ }^{21}$ If respondents say that the do not know the amount or they refuse to answer, they then enter an unfolding brackets sequence (UBs). ${ }^{22}$

The number of questions necessary to extract the income information from self-employed is smaller than for employees. Self-employed are only asked about income in EP045 (and EP045m if it is an euro country) and the associated UBs. EP045 asks respondents what was on average the monthly income before taxes from their business in the last twelve months. Basically we want to get to the notion of gross income for both employees and self employed. Note the difference in the wording: Employees are asked about the last payment, while self-employed are asked about the average payment in the last twelve months.

After being asked all the questions concerning the main job, respondents who have more than one job are asked the same set of questions for the secondary job, except for the sociological questions (EP025 through EP035).

\subsection{Past job situation}

Respondents who report having ever done paid work $($ EP006=1) or report themselves as being retired or unemployed $(\mathrm{EP} 005=$ retired or

\footnotetext{
${ }^{21}$ The SHARE questionnaire allows also for outcomes like "Don't Know" or "Refuse".

22 Obviously, in non-euro countries (Switzerland, Denmark and Sweden), amounts are only asked in local currency. See Brugiavini, Croda, Paccagnella, et al. (2005) for details on the UBs sequence in EP. See also section 3.5 below.
} 
EP005=unemployed) are asked detailed questions about the last job they had before entering the current status: EP048 through EP070. The past job questions mirror the questions asked for the current job: in which year did the last job end, number of years working at that job, whether respondents were working as employee, civil servants, or self-employed, job title, qualifications needed, sector of activity, and responsibility at work.

The past job part of the questionnaire ends with a set of (close ended) questions (EP064-EP070) asking respondents the reason why they left the job market/are now in the current status. ${ }^{23}$ Retirees $($ EP005 $=$ retired) are asked for which reason they retired (EP064), and also whether retirement has been mainly a relief or a concern for them (EP065), and whether in the last job, there were opportunities to keep working, either full or part-time, after the official retirement age (EP059). The prevalence of reasons for retirement among retirees is summarized in Table A3 in Appendix A. About $15 \%$ of retirees report having retired because of health -related problems. However, a substantial proportion of them report eligibility for retirement, early- or pre-retirement as a cause. In particular, among men, the fraction of men that retired because they were given an early retirement option is equivalent to the fraction that retired for health reasons.

Unemployed respondents (EP005=unemployed) are asked how they became unemployed. Permanently sick or disabled respondents (EP005=permanently sick or disabled) who have done some paid work in the past $($ EP006=1) are asked whether the current status was caused by their prior working activities. Finally, homemakers (EP005= homemaker) who have done some paid work in the past $($ EP006=1) are asked why they stopped working.

\section{4. Last year income and future benefits entitlements}

The last part of EP deals with last year income and future benefits entitlements and is asked to all respondents.

\footnotetext{
${ }^{23}$ Multiple choices are allowed.
} 


\section{4.1. Last year income}

A crucial role of EP is to produce a detailed picture of the individual income and benefits received in 2003, the calendar year preceding the interview. EP accomplishes this by investigating three major components of individual income: income from earnings, income from pensions and income from regular payments and benefits. For each of these components, EP first asks whether respondents received or not that type of income (in the following "ownership"), then, in case respondents "own" that type of income, EP asks about the amount (and related questions) of that income source. ${ }^{24}$

Following the set-up adopted for the current income, in the last year income part, EP distinguishes between earnings from employment (EP204, EP205, EP205m, and associated UBs) and earnings from self-employment (EP206, EP207, EP207m, and associated UBs). However, the wording of the questions is very similar, asking what was the approximate income from employment (EP205) and from self-employment (EP207) before any tax and contribution in the year 2003.

Europe is very heterogeneous, and social security systems across European countries are characterized by complex pensions and benefits schemes. $^{25}$ In an effort to capture this complexity, EP needs to rely on multiple questions: EP071 and related questions (EP071, EP213, EP208, EP078, EP078m, EP074m, EP075, EP081, EP082, EP082m) address public and private occupational pensions and public benefits, EP089 and related questions (EP089, EP096, EP094, EP094m, EP090, EP091, EP092, EP209, EP209m) address private pensions and regular payments.

EP071 asks whether respondents received income from any of the following sources in 2003:

1. public old age pension

2. public early retirement or pre-retirement pension

\footnotetext{
${ }^{24}$ Following the procedure implemented for current income, income amounts are first asked in the local currency. Next, in the euro-countries, if respondents say that they do not know the amount or they refuse to answer to the local currency question, EP asks for the amount in the pre-euro currency. If respondents say that the do not know the amount or they refuse to answer, they then enter an unfolding brackets sequence. Obviously, the pre-euro amount question is not asked in non-euro countries.

${ }^{25}$ See the MISSOC Tables for an up-to-date description of the difference country-specific institutions.
} 
3. public disability insurance

4. public unemployment benefit or insurance

5. public survivor pension from your spouse or partner

6. public invalidity or incapacity pension

7. war pension

8. private (occupational) old age pension

9. private (occupational) early retirement pension

10. private (occupational) disability or invalidity insurance

11. private (occupational) survivor pension from your spouse or partner's job

or none of these. ${ }^{26}$ For each source of income received, respondents are then asked in which year they first received it (EP213), for how many months altogether they received it (EP208 - "time limit"), how large was the average payment before taxes (EP078, EP078m, and associated UBs), which period that payment covered (EP074 - "periodicity", EP075), whether they received any additional or lump-sum payment from such an income source, and if so, about how much was such payment before taxes (EP081, EP082, EP082m, and associated UBs).

Given the important role played by these sources of income for the SHARE target population, the aim of the list of categories in EP071 was to be as exhaustive as possible, taking into account the trade-off between parsimony of the list and comprehensive coverage of the alternatives offered by country-specific social security systems.

Ex-ante harmonization in the questions has been a foremost priority in the whole project. However, EP071 (and the associated questions) is one instance where ex ante harmonization turned out to be most difficult, because of the heterogeneity of social security systems across SHARE participant countries. To deal with these institutional differences, it has been necessary to allow for country-specific deviations from the generic version of the questionnaire, so that in the country-specific questionnaires some countries shut down some categories which do not apply to them, and other

\footnotetext{
${ }^{26}$ Multiple choices are allowed.
} 
countries filled these categories with other pensions and benefits. Appendix D.1 summarizes all the country-specific deviations from the generic questionnaire for EP071 (and associated questions). The first column contains the income source listed in the generic questionnaire, the next columns propose the specific deviations introduced by each SHARE country, where they apply. For instance, Sweden does not have "war pensions", which are listed under category 7 in the generic questionnaire, and rather than skipping category 7 , it asks as category 7 "occupational pensions for municipal and local government workers". Sweden has several other country-specific deviations. Among others, "disability insurance benefits" replace category 2, and "survivor benefits" replace category 3. Italy includes "social pensions" among public old age pensions in category 1, and "assegno di accompagnamento" among public disability insurance in category 3. Germany does not ask for public invalidity or incapacity pensions (category 6) or private occupational early retirement pensions (category 9).

Table A4 in Appendix A shows the average age at which current recipients first collected a specific benefit or pension, by gender and country, for all respondents who receive old age pension or early retirement or disability benefits from public or private sources, thus providing yet another perspective on the effect of welfare arrangements and labor market configurations for exits from the labor market. The table highlights a striking variability in the average effective retirement age across countries: for men the lowest is Italy at 57.1 and the highest is Denmark at 64.1.

After being asked EP071 and the associated questions, Austrian and German respondents are asked about payments received from long term care insurance: whether they received any regular payments from a long-term care insurance in 2003 (EP085), how much they received each month (EP086, EP086m, and associated UBs), and finally whether they ever applied for it and the outcome of the application (EP087, EP088). ${ }^{27}$

\footnotetext{
${ }^{27}$ Austria and Germany are the only two SHARE countries which explicitly provide long-term care insurance.
} 
Next, all respondents are asked about private pensions and regular payments, in EP089 and related questions (EP089, EP096, EP094, EP094m, EP090, EP091, EP092, EP209, EP209m). The structure and organization of these questions is similar to those of EP071 and the associated questions, except that respondents are not asked the year in which they first received these payments. Specifically, EP089 asks whether respondents received any of the following regular payments or transfers in 2003:

1. life insurance payment

2. private annuity/private personal pension

3. private health insurance payment

4. alimony

5. regular payments from charities

or none of these. ${ }^{28}$ For each source of income received, respondents are then asked for how many months altogether they received it (EP096), how large was the average payment before any taxes and contributions (EP094, EP094m, and associated UBs), which period that payment covered (EP090, EP091), whether they received any additional or lump-sum payment from such an income source during 2003, and if so, about how much was such payment before any taxes and contributions (EP092, EP209, EP209m, and associated UBs). Ex-ante harmonization for this set of question was successful, and there was no need to allow for country-specific deviations, except for Germany not asking for "regular payments from charities" and France not asking for "private health insurance payment".

Figure 6 organizes the answers to EP071 and EP089 in three groups: public pensions (public old age pension, public early retirement or preretirement pension, public disability insurance, public unemployment benefit or insurance, public survivor pension from one' spouse or partner,

${ }^{28}$ Multiple choices are allowed. 
Figure 6: Public and Private Pensions and Other Benefits
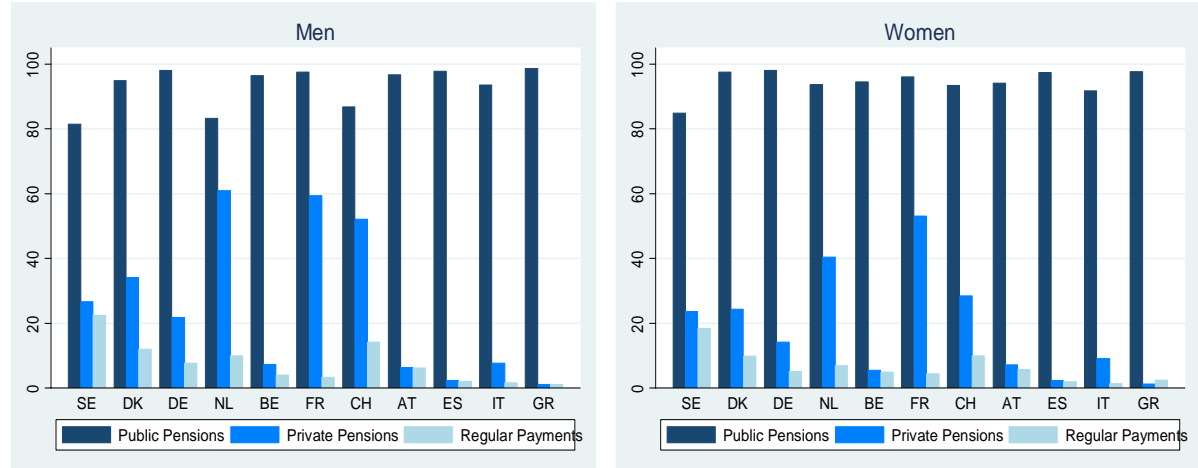

public invalidity or incapacity pension, war pension), private occupational pensions (private occupational old age pension, private occupational early retirement pension, private occupational disability or invalidity insurance, private occupational survivor pension from spouse or partner's job) and regular payments (EP089) and shows in bar-charts disaggregated by country and gender the prevalence of "ownership" of these income sources among those SHARE respondents who report receiving at least one of them. Notice that a respondent may receive more than one of each of these income sources at the same time. The heterogeneity across countries in the development of the second pillar stands out. In the Netherlands, France and Switzerland, more than half of the men receive some kind of private occupational pension. In contrast, these types of pensions are still not popular at all in the Mediterranean countries (Spain, Italy and Greece), even though in Italy it seems like the recent reforms have started having an impact. The pattern among women is similar to the patter among men, except for lower percentages values.

\subsubsection{Future benefits entitlements}

Finally, all respondents are asked about future pension entitlements in EP097 through EP109.

EP097 and EP098 ask whether they are entitled to at least one pension among:

1. public old age pension 
2. public early retirement or pre-retirement pension

3. public disability insurance; sickness/invalidity/incapacity pension

4. private (occupational) old age pension

5. private (occupational) early retirement pension

which they do not currently receive, and to which one in case. Multiple choices are allowed. For each of these future pension claims they are then asked whether it includes also health insurance (EP099), the contribution rate (EP100, asked only to those who self-report as employed or selfemployed in EP005), the name of the institution providing it (EP101, openended), whether participation in that pension plan is compulsory or voluntary (EP102), for how many years respondent have been contributing to it (EP103), whether there is a regular retirement age for it (EP104), whether it allows for early retirement (EP1015) and at what age they plan to collect that pension (EP106). Finally, they are also asked whether they expect to receive a lump sum payment with that pension (EP107) and how much they expect to receive as such a lump-sum (EP108, EP108m, and associated UBs) and the expected replacement rate (EP109).

Allowing for country-specific deviations has been necessary also for the future pension claims. These deviations are displayed in Appendix D.2. Switzerland and Sweden added categories: one and two additional categories, respectively. Sweden is still the country with the highest number of country-specific deviations.

\subsection{Income amounts}

Throughout the EP module, users may find several questions about amounts of income received from different sources. Table A5 in Appendix A summarizes all these questions, specifying whether they ask for a net or gross income concept, and the time period they refer to.

Using the information available for 2003 , it is possible to construct a measure of annual individual income. However, this exercise requires 
particular care because of the complexity of the income notion in different countries.

The "amount" question refers to different time frames across variables. Employment and self-employment income amounts are asked directly as approximate yearly amounts. In contrast, the annual amount of income received from a specific pension or a specific regular payment needs to be calculated from three variables: average payment in 2003, the period covered by the payment, and the number of months in which the respondent has received that payment in 2003. Lastly, long-term care insurance is asked as monthly amount.

In addition, as common in household surveys, income questions suffer from item non-response, especially on amounts. Respondents answering "Don't Know" or "Refuse" to an amount question are asked a number of subsequent questions on whether the amount is larger than, smaller than, or about equal to a given amount. This yields the so-called Unfolding Bracket design, described in Brugiavini, Croda, Paccagnella, et al. (2005) and Kalwij and van Soest (2005).

Brugiavini, Callegaro, Croda, et al. (2006) explain in detail how to construct annual individual income from the EP variables taking into account missing information on some components. At the time of the writing, annual amounts are being generated for the whole SHARE data set and will be made available in the 2007 Public Release of the data. ${ }^{29}$

\section{Conclusions}

The purpose of this paper was to document the EP module in the first wave of the SHARE questionnaire. In order to demonstrate its value, we presented some preliminary descriptive evidence based on the data available to date. Sophisticated analyses were beyond the scope of this paper, meant mostly as a user's guide through the module, but will be the object of future research.

\footnotetext{
${ }^{29}$ Preliminary results, based on Brugiavini, Croda, Paccagnella, et al. (2005), are already available in the SHARE Public Release 1. Brugiavini, Callegaro, Croda, et al. (2006) discuss a more sophisticated methodology, which is in the process of being implemented.
} 
The availability of the first wave of SHARE is providing high value added to the research and policy community. However, population aging is a dynamic process, and to understand its impact we need longitudinal data. At the time of the writing, the design of the second wave of SHARE is under way. The challenges posed to the design of a longitudinal version of the EP module will be the topic of a future paper.

\section{REFERENCES}

Blöndal, S. and S. Scarpetta, 1998. "The Retirement Decision in OECD Countries”, OECD Economics Department Working Papers N 202.

Börsch-Supan, A., A. Brugiavini, H. Jürges, J. Mackenbach, J. Siegrist and G. Weber, eds, 2005. Health, Ageing and Retirement in Europe: First Results from the Survey of Health, Ageing and Retirement in Europe, MEA, Mannheim.

Brugiavini, A., L. Callegaro, E. Croda, D. Christelis, O. Paccagnella and G. Weber, 2006. "Measuring Income and Wealth with Survey Data", University of Salerno, mimeo.

Brugiavini, A., E. Croda, O. Paccagnella, R. Rainato and G. Weber, 2005. "Generated Income Variables in SHARE Release 1", in Börsch-Supan, A. and H. Jürges, eds, Health, Ageing and Retirement in Europe: Methodology, MEA, Mannheim, pp. 105-113.

European Communities, 2006. MISSOC Tables on Social Protection, available at http://ec.europa.eu/employment_social/social_protection/missoc_tables_en. htm (last accessed October 2006)

Gruber, J. and D.A. Wise, eds, 1999. Social Security Programs and Retirement Around the World, The University of Chicago Press, Chicago.

Gruber, J. and D.A. Wise, eds, 2004. Social Security Programs and Retirement Around the World: Micro-estimation, The University of Chicago Press, Chicago.

Kalwij, A. and A. van Soest, 2005. "Item Non-Response and Alternative Imputation Procedures", in Börsch-Supan, A. and H. Jürges, eds, Health, Ageing and Retirement in Europe: Methodology, MEA, Mannheim, pp. 128150. 
Siegrist, J., M. Wahrendorf, O. von dem Knesebeck, H. Jürges and A. Börsch-Supan, 2006. "Quality of Work, Well-being, and Intended Early Retirement of Older Employees - Baseline Results from the SHARE Study", European Journal of Public Health, forthcoming.

United Nations, 2001. World Population Ageing: 1950-2050, Department of Economics and Social Affairs, United Nations Publications, New York 


\section{APPEndix A. AdDitional TABLES}

Table A1. Sample Sizes and Gender Composition of the SHARE Sample

\begin{tabular}{crrrr}
\hline & Number of & \multicolumn{3}{c}{ Number of Individual Respondents } \\
& Households & Individuals & Men & Women \\
\hline SE & 2,140 & 3,067 & 1,424 & 1,643 \\
DK & 1,180 & 1,732 & 785 & 947 \\
DE & 2,003 & 3,020 & 1,386 & 1,634 \\
NL & 1,955 & 3,004 & 1,380 & 1,624 \\
BE & 2,541 & 3,859 & 1,750 & 2,109 \\
FR & 2,111 & 3,287 & 1,424 & 1,863 \\
CH & 716 & 1,010 & 468 & 542 \\
AT & 1,462 & 1,987 & 820 & 1,167 \\
ES & 1,756 & 2,419 & 1,004 & 1,415 \\
IT & 1,780 & 2,568 & 1,136 & 1,432 \\
GR & 1,982 & 2,908 & 1,248 & 1,660 \\
Total & 19,626 & 28,861 & 12,825 & 16,036 \\
\hline
\end{tabular}

Source: Authors' calculations using SHARE Release February 27, 2006. 
Table A2. Self-reported Labor Market Status by Country

\begin{tabular}{|c|c|c|c|c|c|c|}
\hline & Worker & Retired & Unemployed & Disabled & Homemaker & Other \\
\hline \multicolumn{7}{|c|}{ Men } \\
\hline SE & 43.19 & 50.40 & 2.61 & 2.67 & 0.00 & 1.14 \\
\hline DK & 42.60 & 48.40 & 5.21 & 2.22 & 0.14 & 1.42 \\
\hline $\mathrm{DE}$ & 35.15 & 53.45 & 6.25 & 3.79 & 0.17 & 1.19 \\
\hline NL & 39.38 & 44.28 & 2.45 & 8.06 & 0.85 & 4.98 \\
\hline $\mathrm{BE}$ & 28.92 & 57.26 & 3.86 & 4.61 & 0.46 & 4.90 \\
\hline FR & 32.63 & 57.97 & 4.14 & 3.23 & 0.83 & 1.20 \\
\hline $\mathrm{CH}$ & 49.71 & 41.84 & 1.78 & 3.87 & 0.68 & 2.12 \\
\hline AT & 28.19 & 63.84 & 3.41 & 2.17 & 0.53 & 1.85 \\
\hline ES & 32.02 & 57.19 & 3.73 & 4.02 & 0.52 & 2.52 \\
\hline IT & 27.67 & 68.56 & 1.94 & 0.85 & 0.07 & 0.91 \\
\hline GR & 41.83 & 54.47 & 1.69 & 1.13 & 0.24 & 0.64 \\
\hline \multicolumn{7}{|c|}{ Women } \\
\hline SE & 34.20 & 58.33 & 1.74 & 2.35 & 1.54 & 1.84 \\
\hline DK & 33.00 & 55.72 & 3.56 & 3.86 & 2.49 & 1.38 \\
\hline $\mathrm{DE}$ & 22.17 & 54.29 & 3.65 & 1.68 & 16.65 & 1.56 \\
\hline NL & 21.16 & 25.37 & 1.29 & 8.61 & 38.95 & 4.63 \\
\hline $\mathrm{BE}$ & 20.99 & 37.99 & 4.80 & 3.70 & 28.00 & 4.51 \\
\hline FR & 29.13 & 45.57 & 3.20 & 1.88 & 18.62 & 1.60 \\
\hline $\mathrm{CH}$ & 30.50 & 48.42 & 1.71 & 2.42 & 14.87 & 2.09 \\
\hline $\mathrm{AT}$ & 14.16 & 60.93 & 2.17 & 1.04 & 19.85 & 1.84 \\
\hline ES & 14.88 & 16.16 & 2.91 & 4.01 & 55.38 & 6.65 \\
\hline IT & 13.78 & 43.79 & 0.88 & 0.64 & 39.72 & 1.18 \\
\hline GR & 19.58 & 34.73 & 1.76 & 1.39 & 41.39 & 1.15 \\
\hline \multicolumn{7}{|c|}{ All } \\
\hline $\mathrm{SE}$ & 38.69 & 54.36 & 2.17 & 2.51 & 0.77 & 1.49 \\
\hline DK & 37.80 & 52.06 & 4.39 & 3.04 & 1.31 & 1.40 \\
\hline DE & 28.66 & 53.87 & 4.95 & 2.74 & 8.41 & 1.37 \\
\hline NL & 30.27 & 34.82 & 1.87 & 8.33 & 19.90 & 4.80 \\
\hline $\mathrm{BE}$ & 24.95 & 47.63 & 4.33 & 4.15 & 14.23 & 4.71 \\
\hline FR & 30.88 & 51.77 & 3.67 & 2.56 & 9.72 & 1.40 \\
\hline $\mathrm{CH}$ & 40.10 & 45.13 & 1.74 & 3.14 & 7.78 & 2.11 \\
\hline $\mathrm{AT}$ & 21.18 & 62.39 & 2.79 & 1.61 & 10.19 & 1.84 \\
\hline ES & 23.45 & 36.68 & 3.32 & 4.02 & 27.95 & 4.58 \\
\hline IT & 20.73 & 56.17 & 1.41 & 0.75 & 19.90 & 1.05 \\
\hline GR & 30.71 & 44.60 & 1.72 & 1.26 & 20.82 & 0.90 \\
\hline
\end{tabular}

Source: Authors' calculations using SHARE Release February 27, 2006. Based on a sample of 28,842 individual 50+ respondents who reported their current situation. Percentage values. All figures are population-weighted. Standard errors are available upon requests. 
Table A3. Reasons for Retirement

\begin{tabular}{|c|c|c|c|}
\hline Reason for retirement & Men & Women & All \\
\hline Became eligible for public pension & 50.43 & 47.33 & 48.88 \\
\hline Became eligible for private occupational pension & 7.99 & 7.34 & 7.66 \\
\hline Became eligible for a private pension & 2.92 & 1.49 & 2.21 \\
\hline Was offered an early retirement option/widow & 17.10 & 8.26 & 12.68 \\
\hline Made redundant & 7.04 & 5.59 & 6.31 \\
\hline Own ill health & 17.11 & 18.83 & 17.97 \\
\hline Ill health of relative or friend & 1.01 & 3.52 & 2.27 \\
\hline To retire at same time as spouse or partner & 0.85 & 3.78 & 2.32 \\
\hline To spend more time with family & 2.88 & 10.33 & 6.60 \\
\hline To enjoy life & 6.46 & 5.78 & 6.12 \\
\hline $\begin{array}{l}\text { Source: Authors' calculations using SHARE Release F } \\
\text { of individual } 50+\text { respondents who reported being retir } \\
\text { answer to EP064. Percentage values. Columns do not s } \\
\text { for multiple choices. }\end{array}$ & $\begin{array}{l}27,200 \\
P 005 \text { an }\end{array}$ & 5. Based & -missing \\
\hline
\end{tabular}


Table A4. Average Age at First Collection of Current Pension

\begin{tabular}{|c|c|c|c|c|c|c|c|c|c|c|c|}
\hline & $\mathrm{SE}$ & DK & $\mathrm{DE}$ & NL & $\mathrm{BE}$ & FR & $\mathrm{CH}$ & AT & $\mathrm{ES}$ & IT & GR \\
\hline & \multicolumn{11}{|c|}{ WOMEN } \\
\hline $\begin{array}{l}\text { public and private old age } \\
\text { and early retirement pension }\end{array}$ & 63.48 & 64.00 & 60.59 & 63.94 & 59.04 & 60.24 & 61.55 & 56.42 & 61.64 & 56.79 & 58.87 \\
\hline \multirow[t]{2}{*}{ invalidity/incapacity pension } & 52.21 & 48.81 & 49.89 & 45.39 & 43.49 & 42.10 & 48.74 & 50.49 & 51.07 & 51.57 & 47.60 \\
\hline & \multicolumn{11}{|c|}{ MEN } \\
\hline $\begin{array}{l}\text { public and private old age } \\
\text { and early retirement pension }\end{array}$ & 63.52 & 64.12 & 61.23 & 63.34 & 60.67 & 59.71 & 63.73 & 57.81 & 60.63 & 57.12 & 59.90 \\
\hline $\begin{array}{l}\text { disability and } \\
\text { invalidity/incapacity pension }\end{array}$ & 52.73 & 49.62 & 50.59 & 44.95 & 46.06 & 45.68 & 48.14 & 49.23 & 48.59 & 48.54 & 49.08 \\
\hline
\end{tabular}

Source: Authors' calculations using SHARE Release February 27, 2006. 
Table A5. Income Amounts Questions

\begin{tabular}{|c|c|c|c|}
\hline Question & Source of income & Type & $\begin{array}{l}\text { Reference } \\
\text { period }\end{array}$ \\
\hline EP041 & Income from employment & Gross & current \\
\hline EP201 & Income from employment & Net & current $^{+}$ \\
\hline EP045 & Income from self-employment & Gross & current \\
\hline EP205 & Income from employment & Gross & in 2003 \\
\hline EP207 & Income from self-employment & Gross & in 2003 \\
\hline ЕР078 & Pension payment & Gross & in 2003 \\
\hline EP082 & $\begin{array}{l}\text { Additional or lump sum payments } \\
\text { from pensions }\end{array}$ & Gross & in 2003 \\
\hline EP086 & Long term care insurance & & in 2003 \\
\hline EP094 & Regular payments & Gross & in 2003 \\
\hline EP209 & $\begin{array}{l}\text { Additional or lump sum payments } \\
\text { from regular payments }\end{array}$ & Gross & in 2003 \\
\hline
\end{tabular}

${ }^{+}$Current period is Spring 2004. 
APPENDIX B. PAPER VERSION OF THE EP MODULE OF SHARE 2004 CAPI

INSTRUMENT $^{30}$

$[\ldots]$

EP001_INTRODUCTION EMPLOYMENT AND PENSIONS

Now I'm going to ask you some questions about your current employment situation.

1. Continue

EP005_CURRENT JOB SITUATION

Please look at card 21. In general, how would you describe your current situation?

IWER: CODE ONLY ONE

1. Retired

2. Employed or self-employed (including working for family business)

3. Unemployed

4. Permanently sick or disabled

5. Homemaker

97. Other (specify)

IF EP005_(CURRENT JOB SITUATION) = 97. Other (specify)

EP200_ OTHER CURRENT JOB SITUATION

| What other current job situation do you mean?

ENDIF

IF EP005_(CURRENT JOB SITUATION) $<>2$. Employed or self-employed (including working for family business)

|

EP002_ DID NEVERTHELESS ANY PAID WORK LAST FOUR WEEKS

Did you do nevertheless any paid work during the last four weeks,

either as an employee or self-employed, even if this was only for a

few hours?

1. Yes

5. No

IF EP002_(DID NEVERTHELESS ANY PAID WORK LAST FOUR WEEKS) $=5$. No

|

${ }^{30}$ SHARE 2004 version 10 manually edited April 2005. 


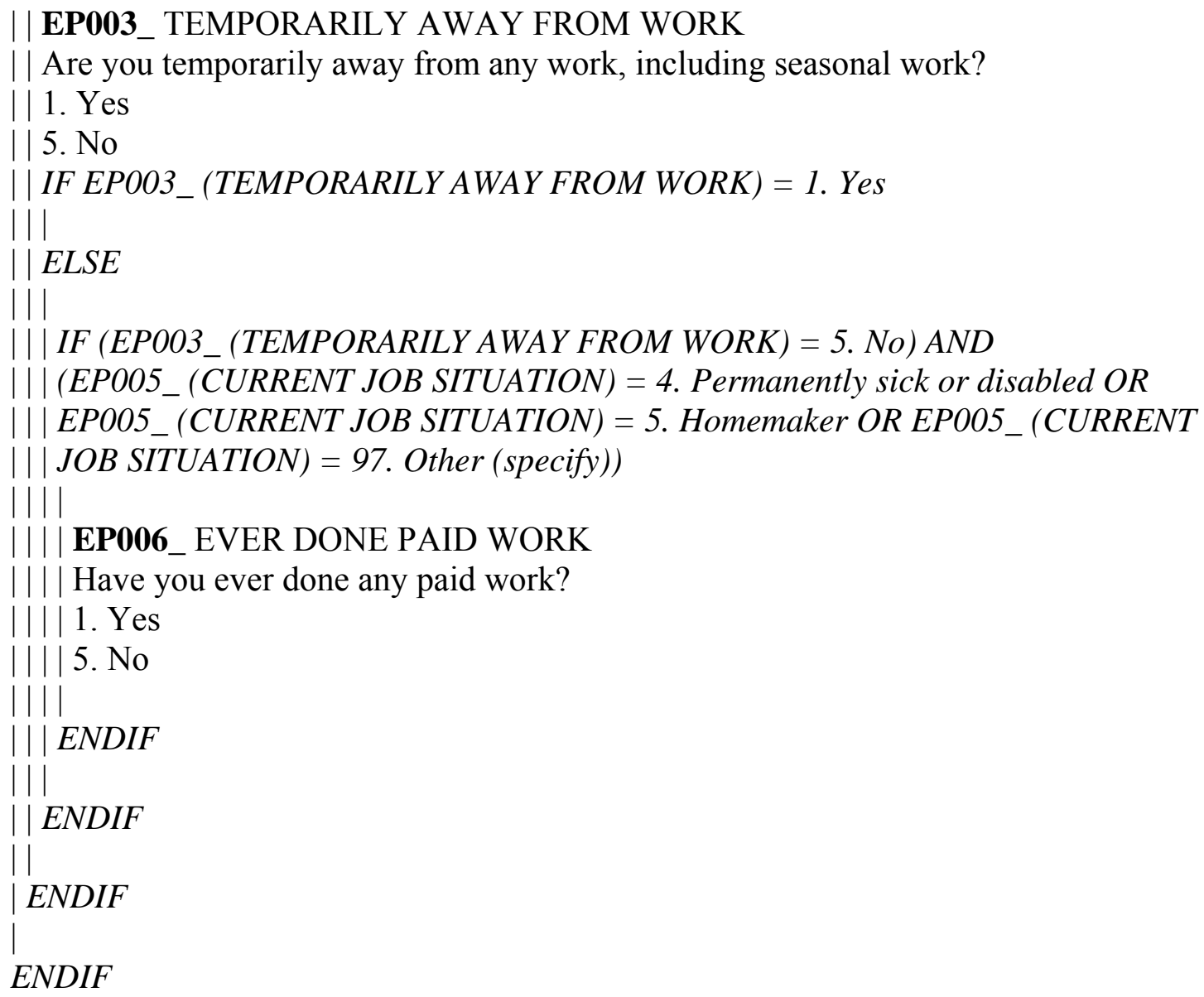

IF EP002_(DID NEVERTHELESS ANY PAID WORK LAST FOUR WEEKS) $=1$. Yes OR EP003_(TEMPORARILY AWAY FROM WORK) = 1. Yes OR EP005_(CURRENT JOB SITUATION) = 2. Employed or self-employed (including working for family business) more than one job) secondary job with the appropriate fill.

Except for questions EP025_(INTRODUCTION WORK DESCRIPTION) to EP037_ (AFRAID HEALTH LIMITS ABILITY TO WORK BEFORE REGULAR RETIREMENT), which are asked once (first time in the loop).

| EP008_ INTRODUCTION CURRENT JOB 
| The following questions are about your [main/secondary] job

in the last month in which you worked.

IWER: INCLUDING SEASONAL JOB. THE MAIN JOB IS THE JOB THE

RESPONDENT IS WORKING MOST HOURS FOR. IF SAME HOURS THAN

I CHOOSE THE ONE THE RESPONDENT GETS MORE MONEY FROM. IF

MORE THAN ONE SECONDARY JOB, CHOOSE THE JOB WITH THE MOST

WORKING HOURS

1. Continue

|

EP009_EMPLOYEE OR A SELF-EMPLOYED

| In your [main/secondary] job are you an employee, a civil

| servant, or a self-employed?

IWER: IF RESPONDENT SAYS HE/SHE WORKS BOTH AS AN EMPLOYED

AND AS A SELF-EMPLOYED, THIS IS TO BE TREATED AS TWO

DIFFERENT JOBS

1. Employee

2. Civil servant

3. Self-employed

|

| EP010_START OF CURRENT JOB (YEAR)

In which year did you start your [main/secondary] job?

| (1900..2004)

(

CHECK: Year should be at least 10 years after year of birth.

| IF EP009_(EMPLOYEE OR A SELF-EMPLOYED) = 1. Employee OR

| EP009_(EMPLOYEE OR A SELF-EMPLOYED) = 2. Civil servant

|

| EP011_TERM OF JOB

| In this job, do you have a short-term or a permanent contract?

| IWER: BY SHORT-TERM WE MEAN LESS THAN 3 YEARS

|| 1. Short-term

| 2. Permanent

||

| | EP012_ TOTAL CONTRACTED HOURS PER WEEK IN THIS JOB

| What are your total basic or contracted hours each week in this job,

| excluding meal breaks and any paid or unpaid overtime?

|| $(0.0 . .168 .0)$

$\Pi$

| ENDIF

EP013_TOTAL HOURS WORKED PER WEEK

| [Regardless of your basic contracted hours] [how many/How

| many] hours a week do you usually work in this job, excluding meal 


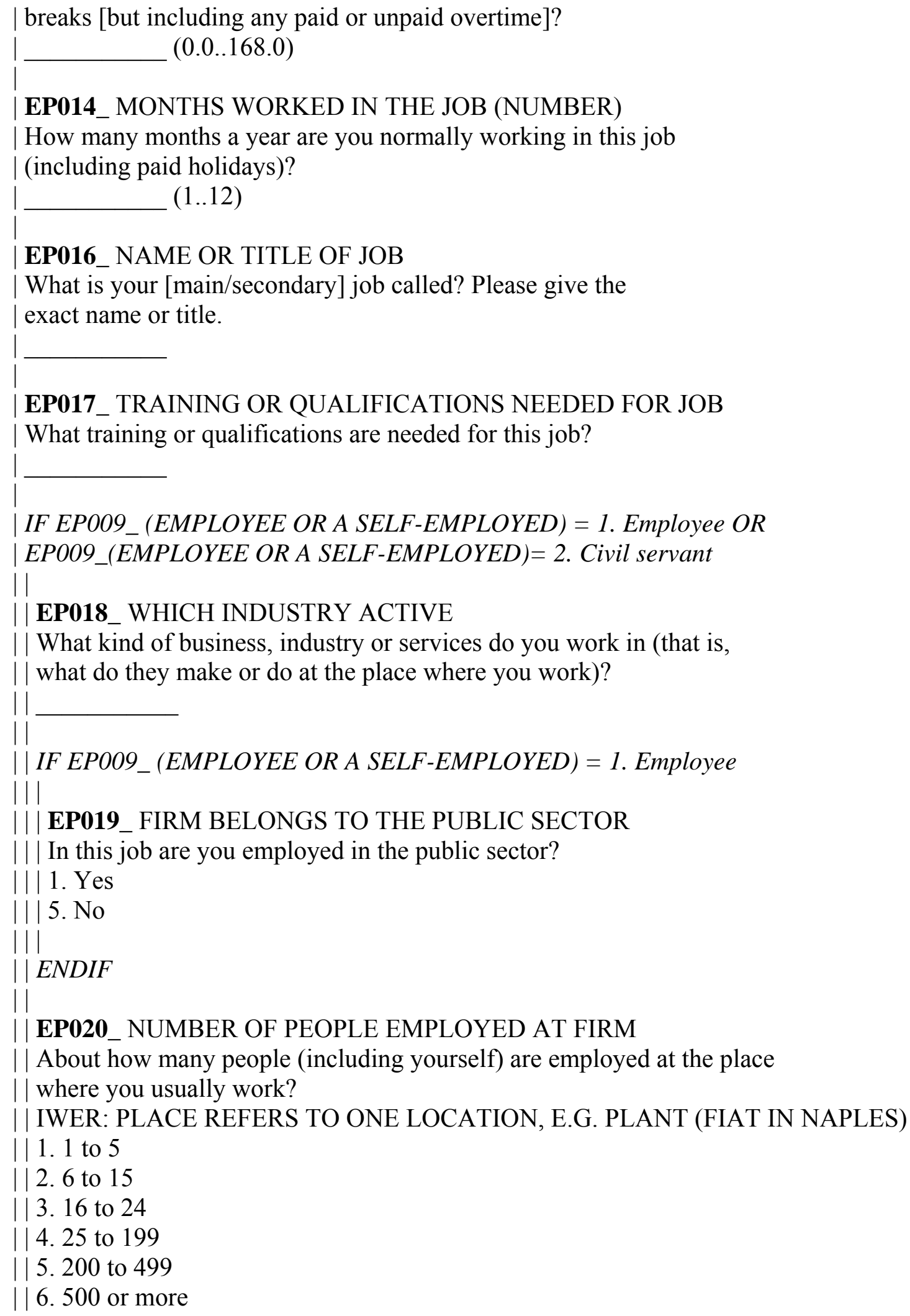

| 6.500 or more 


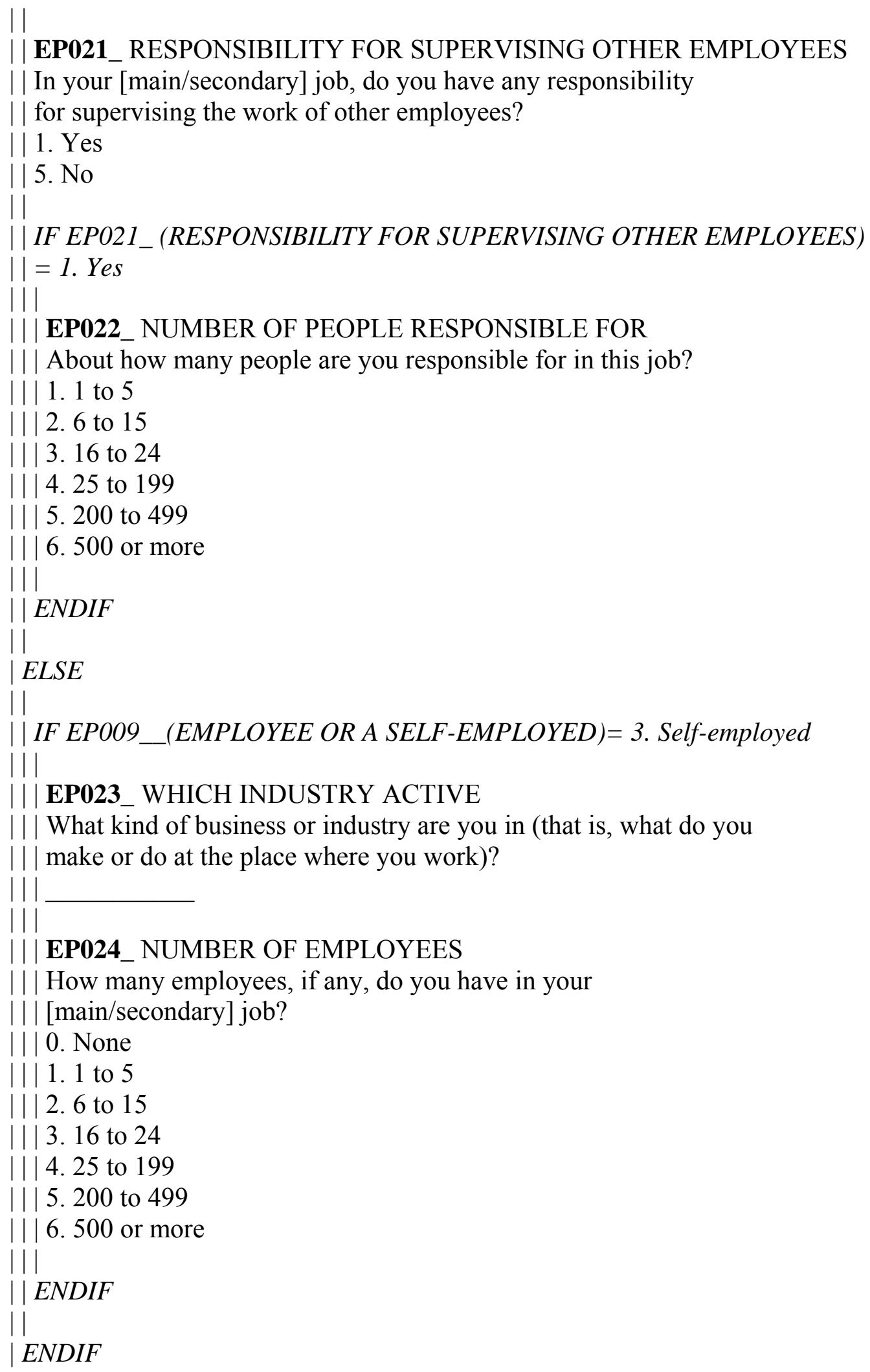




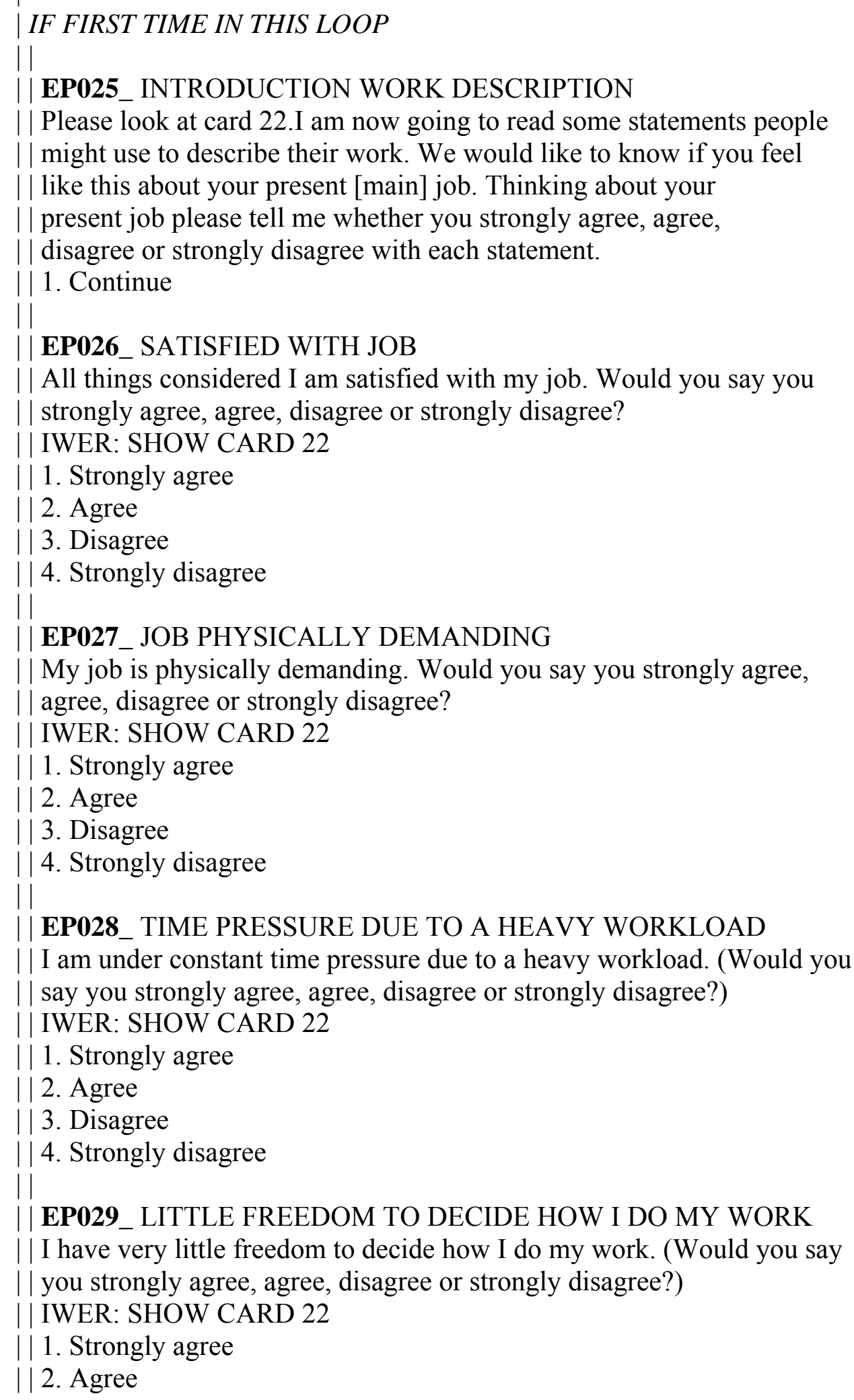




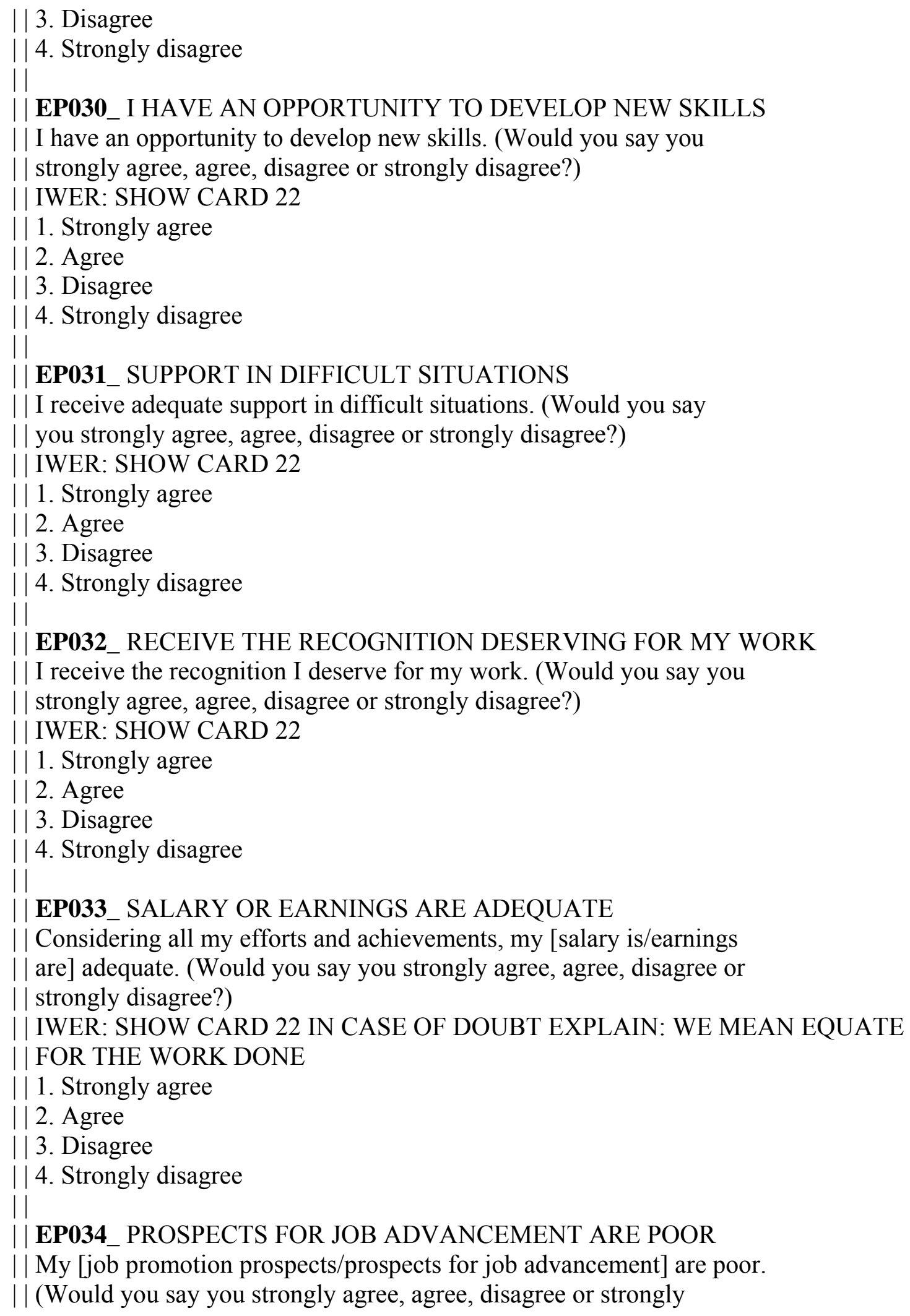




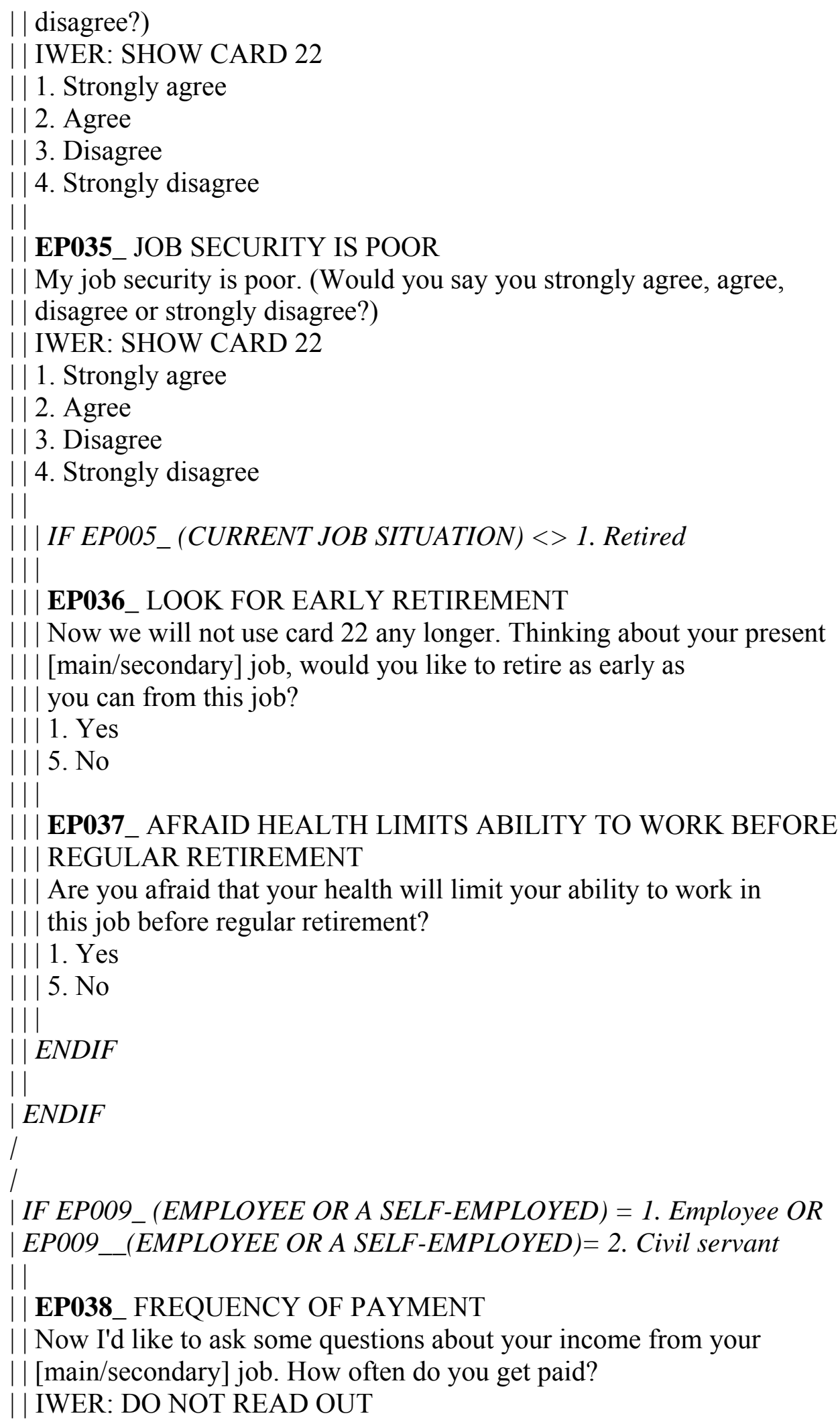


|| 1. Every week

||2. Every two weeks

| 3. Every calendar month/4 weeks

| 4. Every three months/13 weeks

| 5 . Every six months/26 weeks

| 6. Every year/12 months/52 weeks

| 97. Other frequency (specify)

|

|| IF EP038_(FREQUENCY OF PAYMENT) = 97. Other frequency

| (specify)

| | |

| || EP039_OTHER FREQUENCY OF PAYMENT

| ||

| | IWER: CODE OTHER FREQUENCY

|l

| |

|| ENDIF

||

| | EP041_TAKEN HOME FROM WORK BEFORE TAX

| | Before any deductions for tax, national insurance or pension and

| health contributions, union dues and so on, about how much was the

| last payment?

| IWER: AMOUNT IN [\{local currency $\}]$

| enter an amount

|

| IF EP041_(TAKEN HOME FROM WORK BEFORE TAX) = EMPTY AND

| MN004_(EURO COUNTRY) $=1$. Yes

||

| | | EP041M TAKEN HOME FROM WORK BEFORE TAX

|| | Before any deductions for tax, national insurance or pension and

|| health contributions, union dues and so on, about how much was your

| | last payment?

| | | IWER: AMOUNT IN [\{pre-euro currency\}]

| | | enter an amount

|| |

|| ENDIF

|

CHECK: Please enter a value.

| IF EP041_(TAKEN HOME FROM WORK BEFORE TAX) = NONRESPONSE

| | OR EP041M (TAKEN HOME FROM WORK BEFORE TAX) = NONRESPONSE

|| |

|| | Unfolding Brackets

||

|| ENDIF 


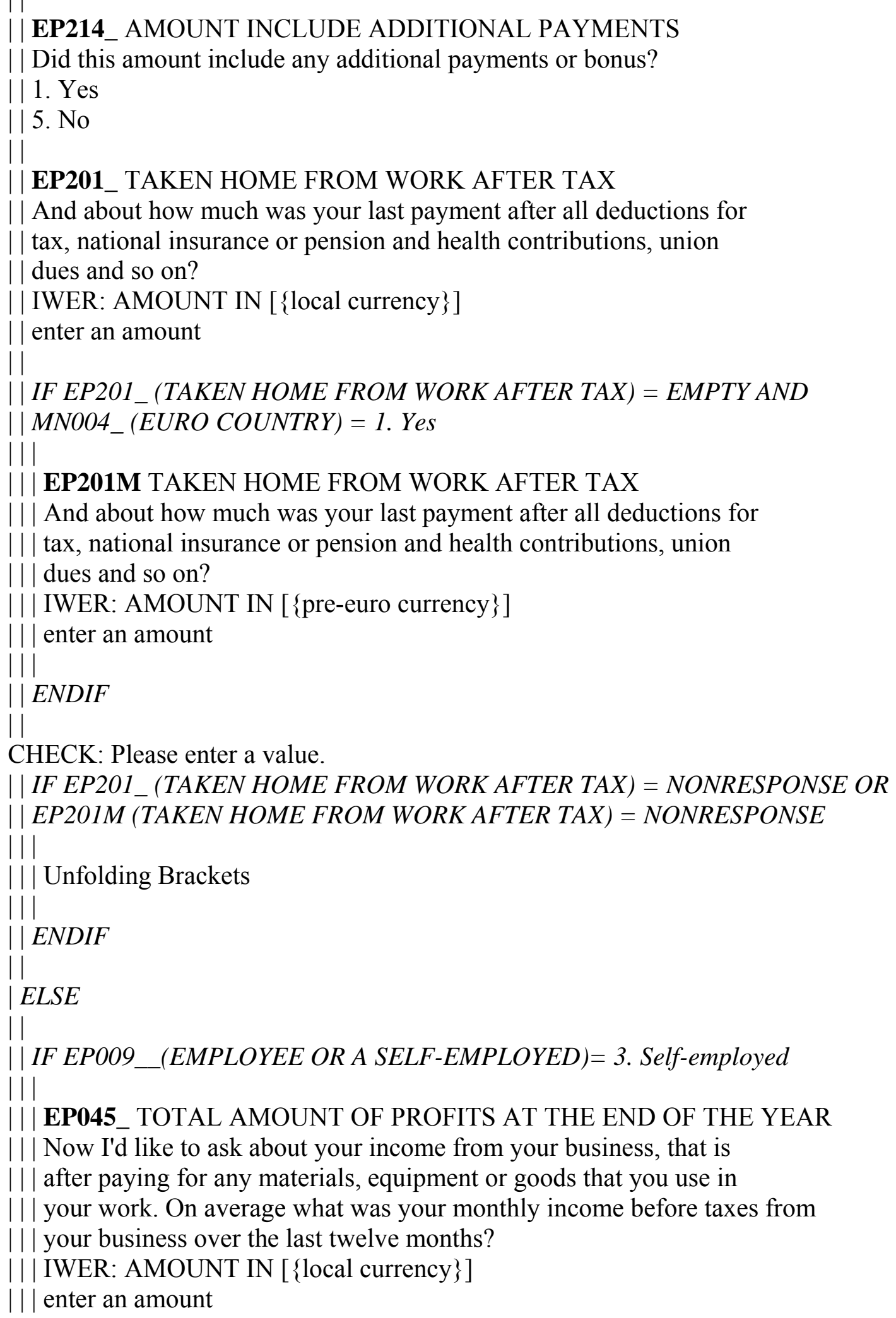




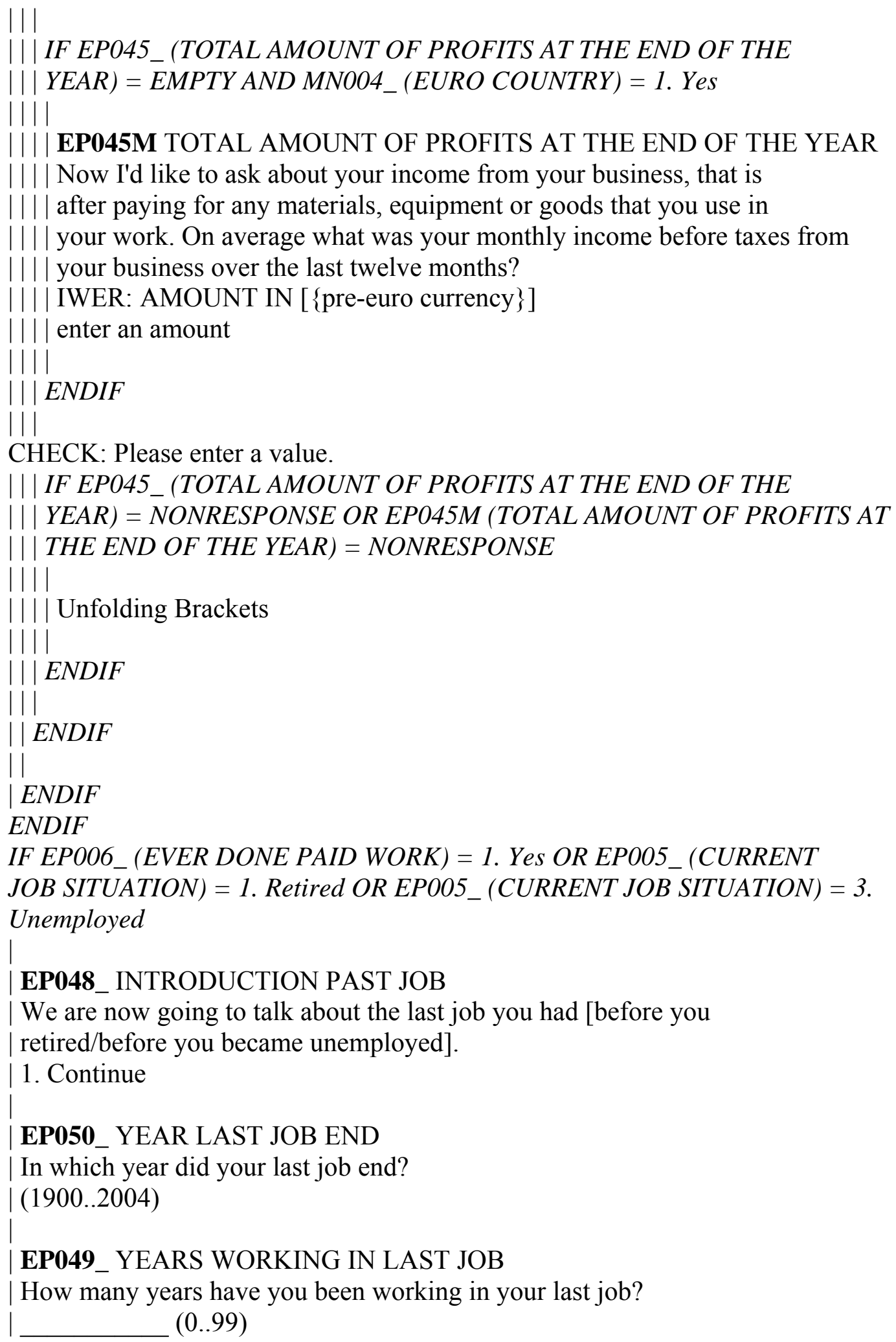


| EP051_EMPLOYEE OR A SELF EMPLOYED IN LAST JOB

In this last job were you an employee or self-employed?

1. Employee

2. Civil servant

3. Self-employed

|

| EP052_NAME OR TITLE OF JOB

| What was your job called? Please give the exact name or title.

| EP053_ TRAINING OR QUALIFICATIONS NEEDED FOR JOB

What training or qualifications were needed for this job?

IF EP051_(EMPLOYEE OR A SELF EMPLOYED IN LAST JOB) $=1$.

Employee OR EP051_(EMPLOYEE OR A SELF EMPLOYED IN LAST JOB) =

2. Civil servant

||

| | EP054_WHICH INDUSTRY ACTIVE

|| What kind of business, industry or services did you work in (that is,

| | what did they make or do at the place where you worked)?

||

|

|| IF EP051_(EMPLOYEE OR A SELF EMPLOYED IN LAST JOB) $=1$.

| Employee

| |

| | | EP055_FIRM BELONGED TO THE PUBLIC SECTOR

| || In this job were you employed in the public sector?

|| 1 . Yes

|| 5. No

| | |

|| ENDIF

||

| | EP056_NUMBER OF PEOPLE EMPLOYED AT FIRM

|| About how many people, including yourself, were employed at the place

| | where you usually worked?

| IWER: PLACE REFERS TO ONE LOCATION, E.G. PLANT (FIAT IN NAPLES)

|| 1.1 to 5

|| 2.6 to 15

|| 3.16 to 24

| 4.25 to 199

| 5.200 to 499

| 6.500 or more

|| 


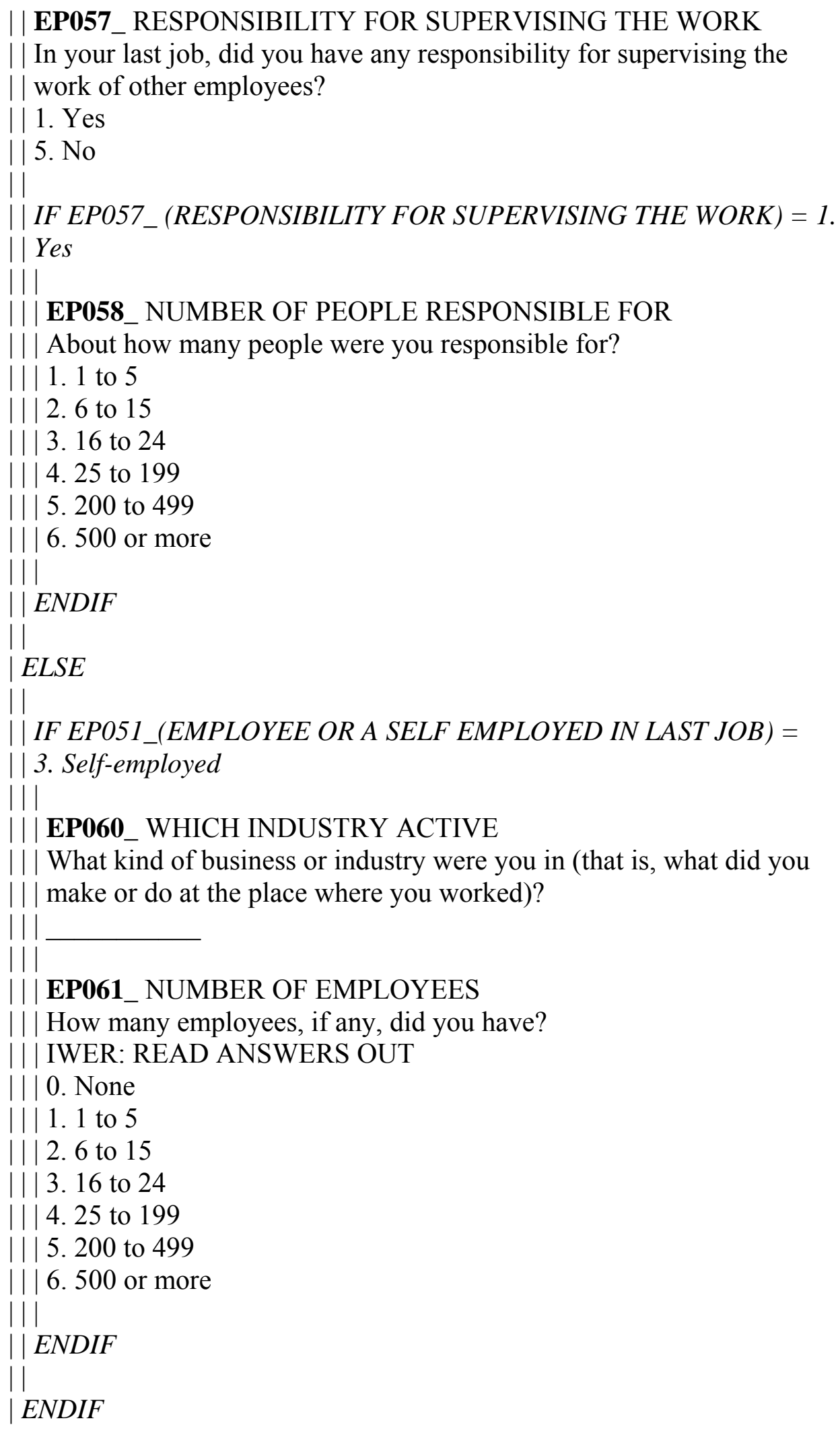




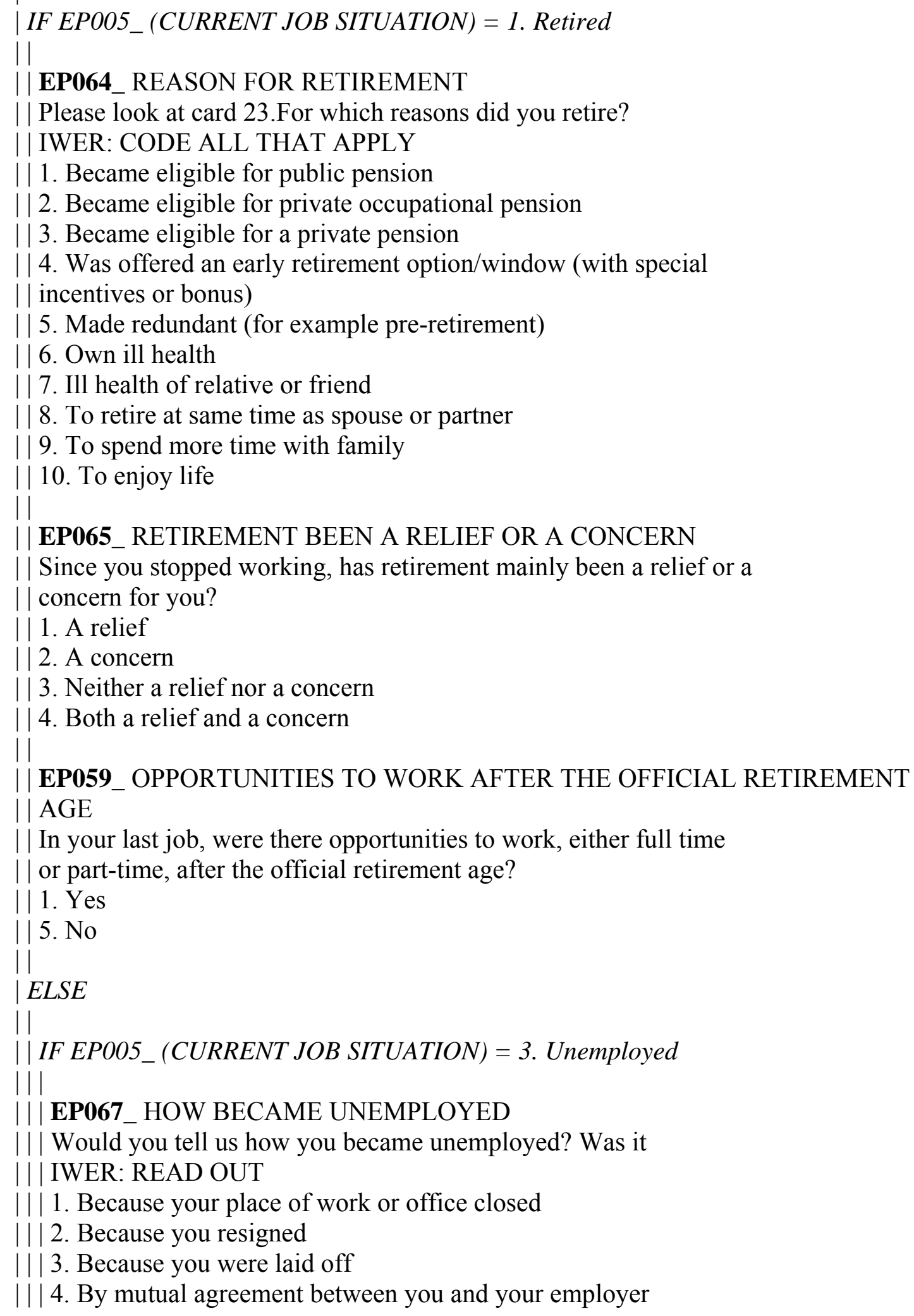




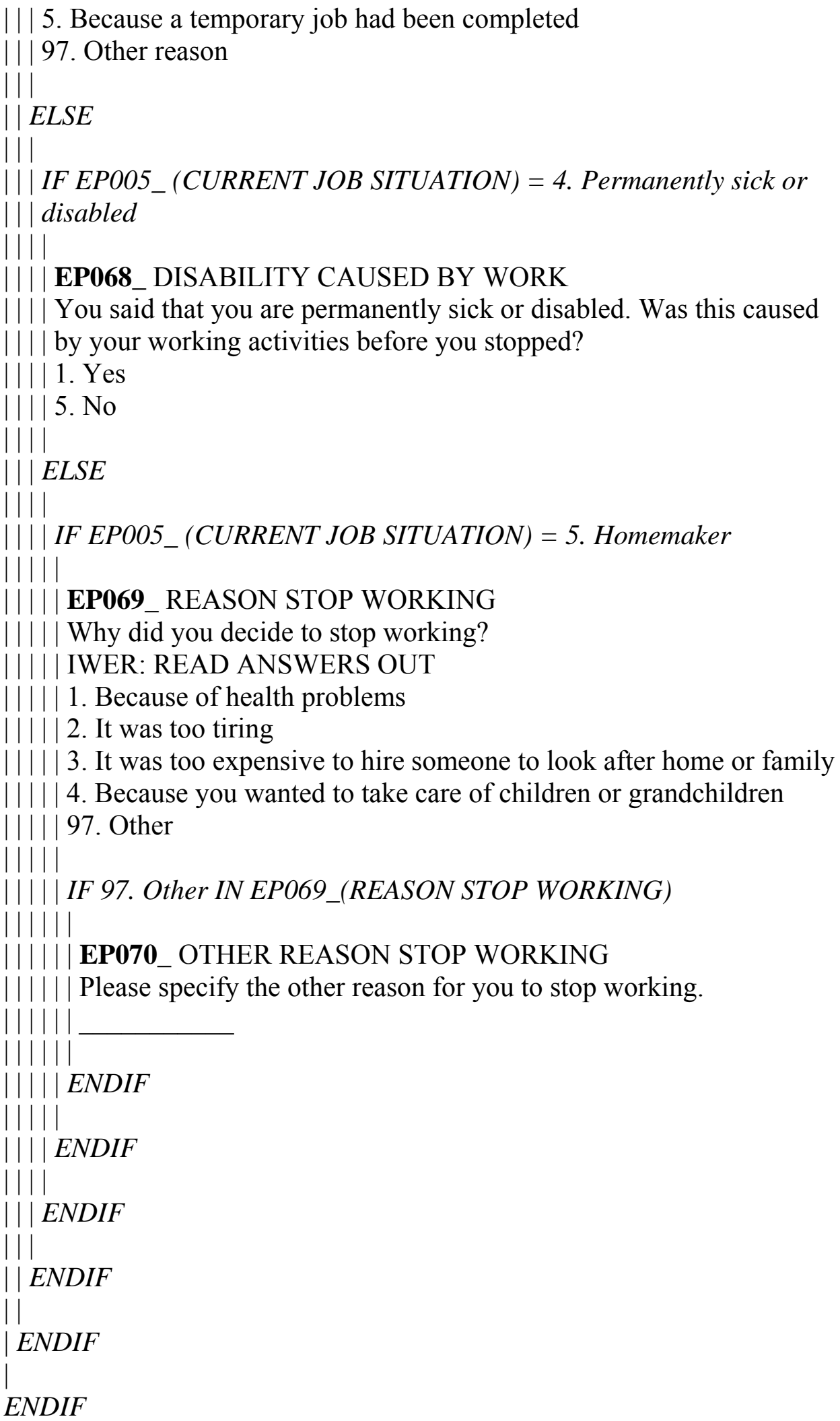




\section{EP203_INTRO INDIVIDUAL INCOME}

We would now like to know more about your earnings and income during the last year, that is in 2003 .

1. Continue

\section{EP204_ANY EARNINGS FROM EMPLOYMENT 2003}

Have you had any earnings at all from employment in 2003?

1. Yes

5. No

IF EP204_(ANY EARNINGS FROM EMPLOYMENT 2003) $=1$. Yes

|

| EP205_EARNINGS EMPLOYMENT PER YEAR BEFORE TAXES

| Before any tax and contributions, what was your approximate income

from employment in the year 2003?

| IWER: AMOUNT IN [\{local currency $\}$ ]

| enter an amount

IF EP205_(EARNINGS EMPLOYMENT PER YEAR BEFORE TAXES) = EMPTY

| AND MNO04_(EURO COUNTRY) $=1$. Yes

|

| | EP205M EARNINGS EMPLOYMENT PER YEAR BEFORE TAXES

| Before any tax and contributions, what was your approximate income

|| from employment in the year 2003?

| | IWER: AMOUNT IN [\{pre-euro currency\}]

| enter an amount

|

| ENDIF

|

CHECK: Please enter a value.

| IF EP205_(EARNINGS EMPLOYMENT PER YEAR BEFORE TAXES) = | NONRESPONSE OR EP205M (EARNINGS EMPLOYMENT PER YEAR BEFORE

$\mid$ TAXES) $=$ NONRESPONSE

|

| | Unfolding Brackets

|

| ENDIF

|

ENDIF

EP206_INCOME FROM SELF-EMPLOYMENT 2003

Have you had any income at all from self-employment or work for a family business in 2003 ?

1. Yes

5. No

IF EP206_(INCOME FROM SELF-EMPLOYMENT 2003) $=1$. Yes 


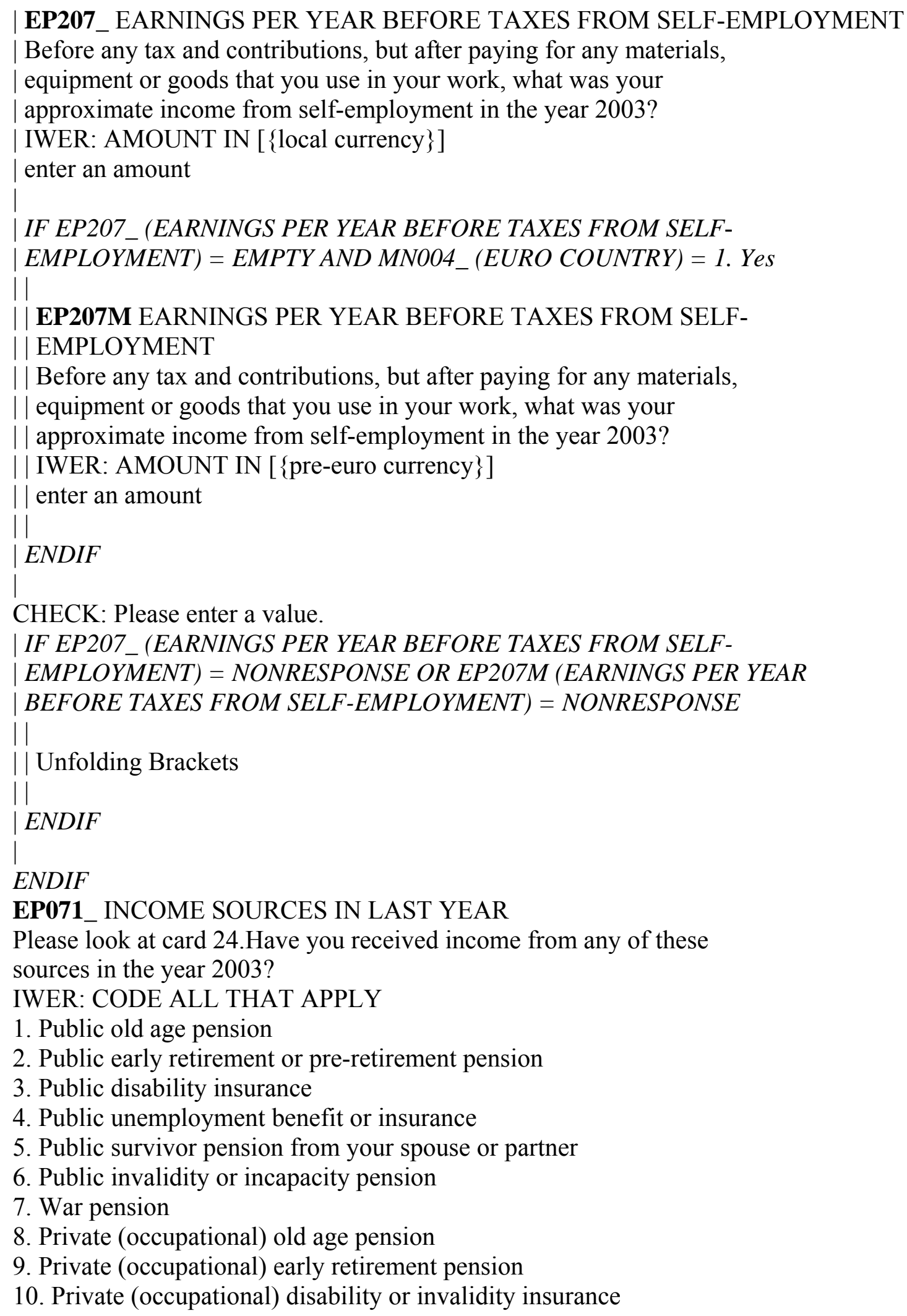

Please look at card 24. Have you received income from any of these sources in the year 2003?

IWER: CODE ALL THAT APPLY

1. Public old age pension

2. Public early retirement or pre-retirement pension

3. Public disability insurance

4. Public unemployment benefit or insurance

5. Public survivor pension from your spouse or partner

6. Public invalidity or incapacity pension

7. War pension

8. Private (occupational) old age pension

9. Private (occupational) early retirement pension

10. Private (occupational) disability or invalidity insurance 
11. Private (occupational) survivor pension from your spouse or partner's job

96. None of these

CHECK: You cannot select 'None of the above' together with any other answer.

Please change your answer.

LOOP cnt $=1$ TO 11

\section{| EP208_HOW MANY MONTHS RECEIVED INCOME SOURCE}

| | For how many months altogether did you receive [the public old age

| | pension/the public early retirement or pre-retirement pension/the

| | public disability insurance/the public unemployment benefit or

| | insurance/the public survivor pension from your spouse or partner/the

| | public invalidity or incapacity pension/the war pension/the private

| ( occupational) old age pension/the private (occupational) early

| | retirement pension/the private (occupational) disability or

| | invalidity insurance/the private (occupational) survivor pension from

| | your spouse or partner's job] in 2003?

|

||

| | EP078_AVERAGE PAYMENT OF PENSION IN 2003

| | Before taxes, about how large was the average payment of [your public

| | old age pension/your public early retirement or pre-retirement

| | pension/your public disability insurance/your public unemployment

| | benefit or insurance/your public survivor pension from your spouse or

| | partner/your public invalidity or incapacity pension/your war

| | pension/your private (occupational) old age pension/your private

| ( occupational) early retirement pension/your private (occupational)

|| disability or invalidity insurance/your private (occupational)

| | survivor pension from your spouse or partner's job] in 2003?

| IWER: AMOUNT IN [\{local currency $\}]$

| | enter an amount 


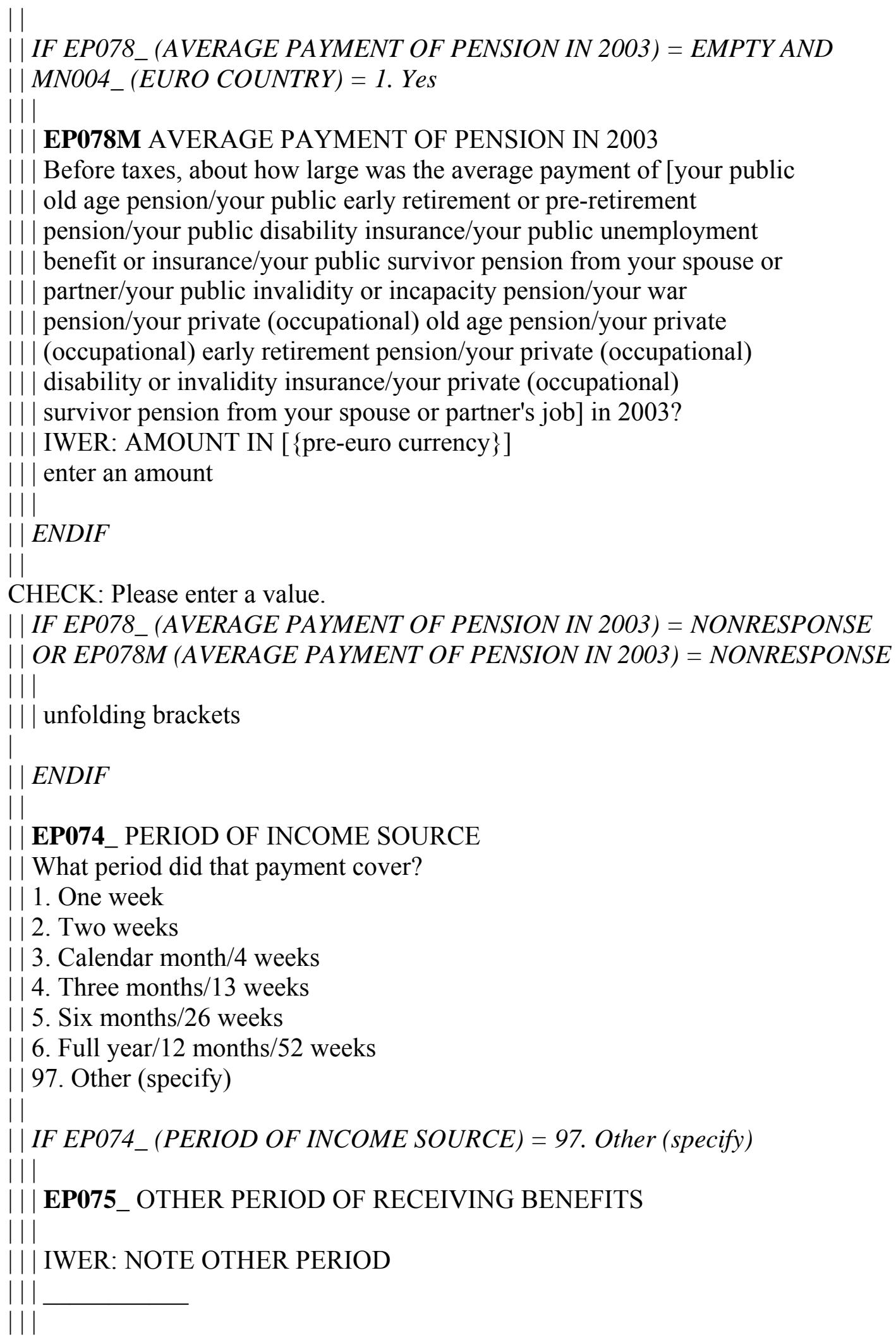




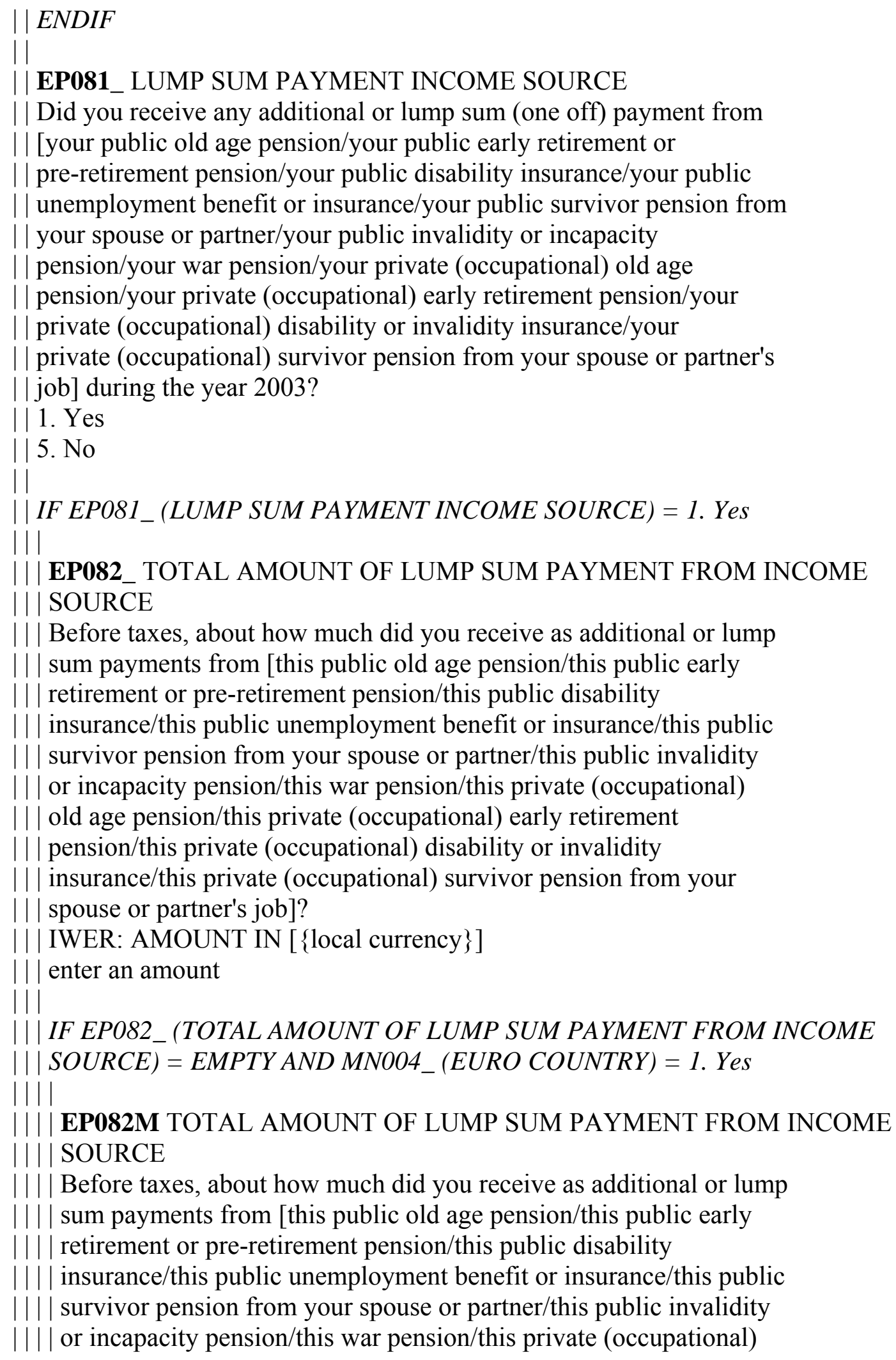




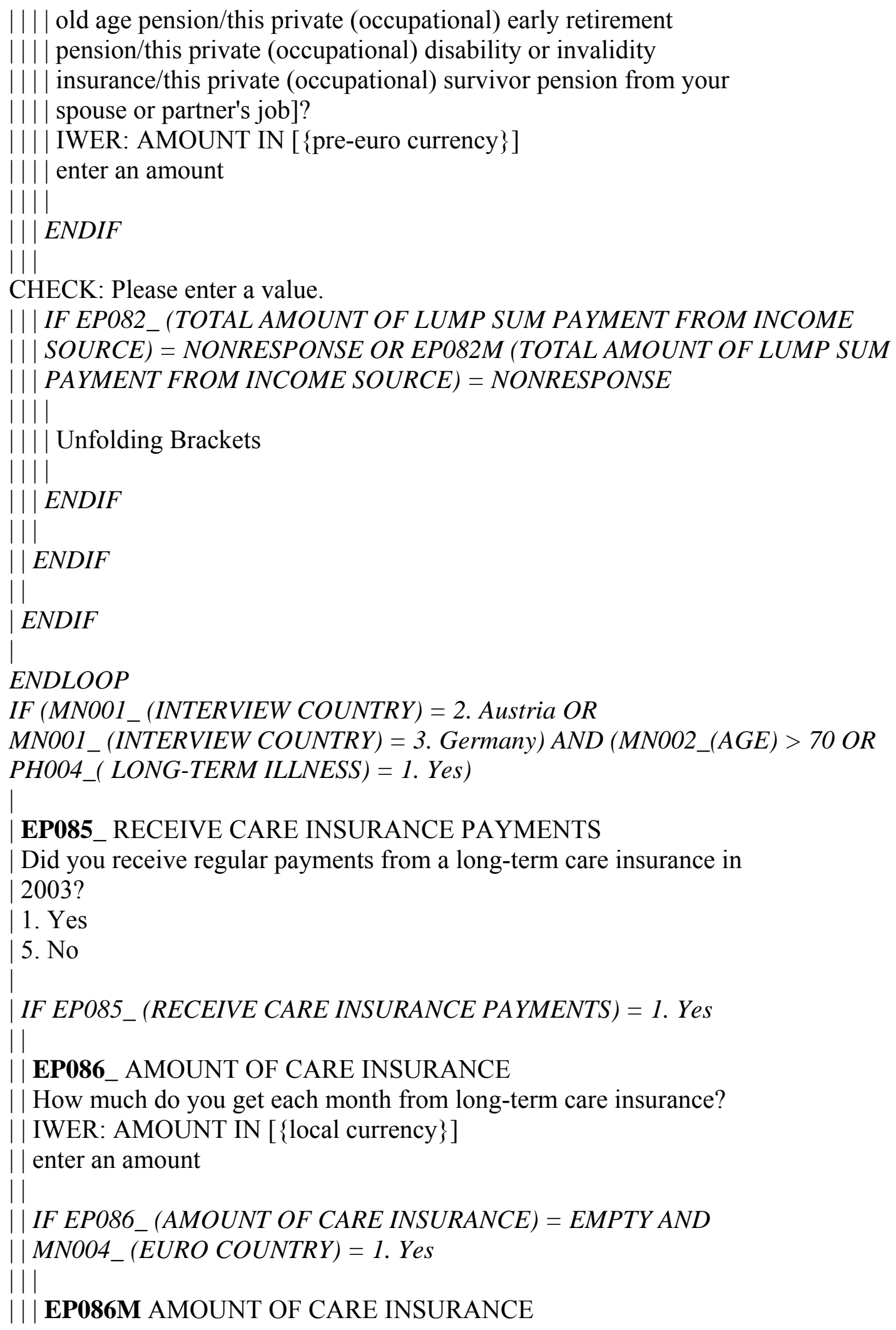




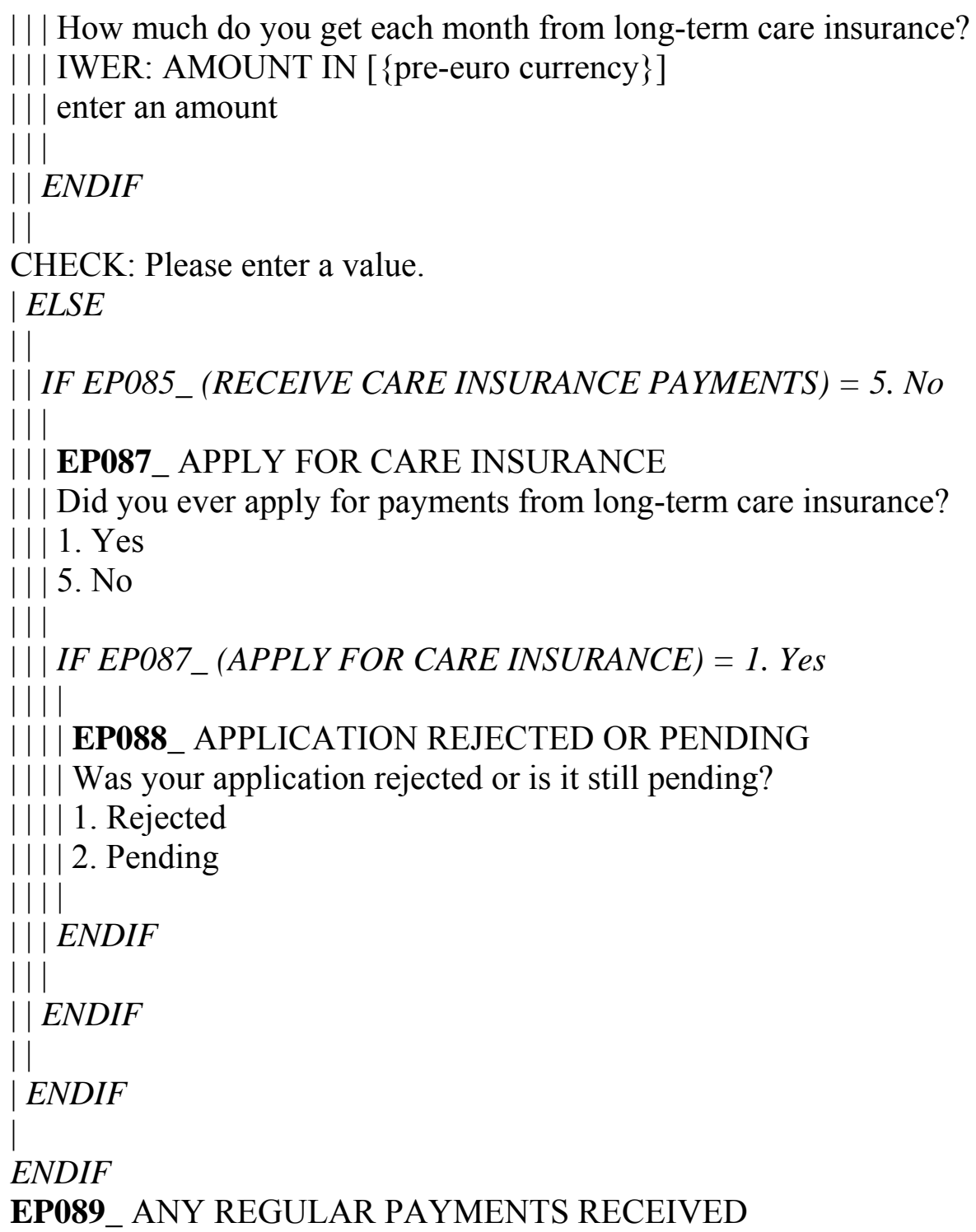




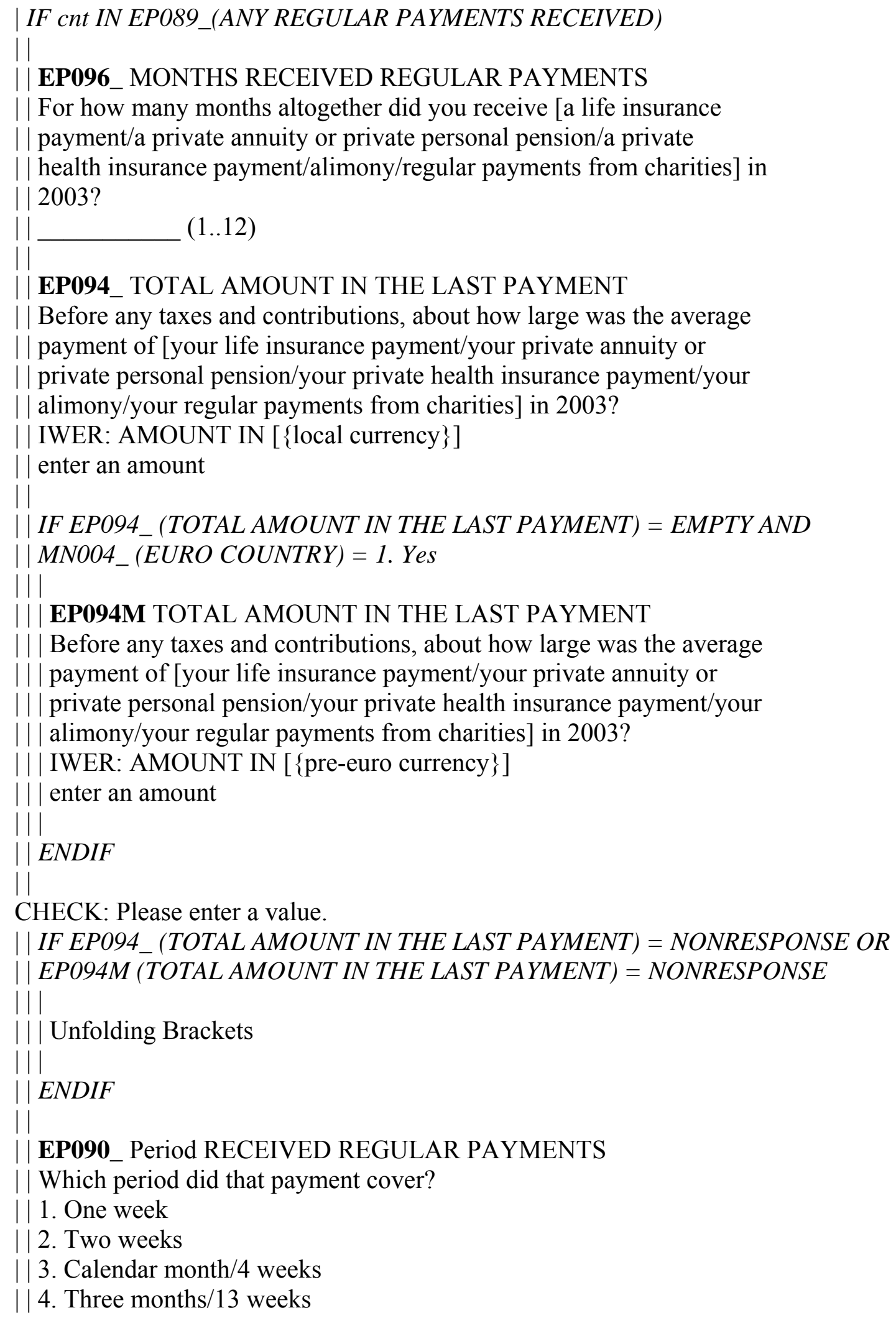




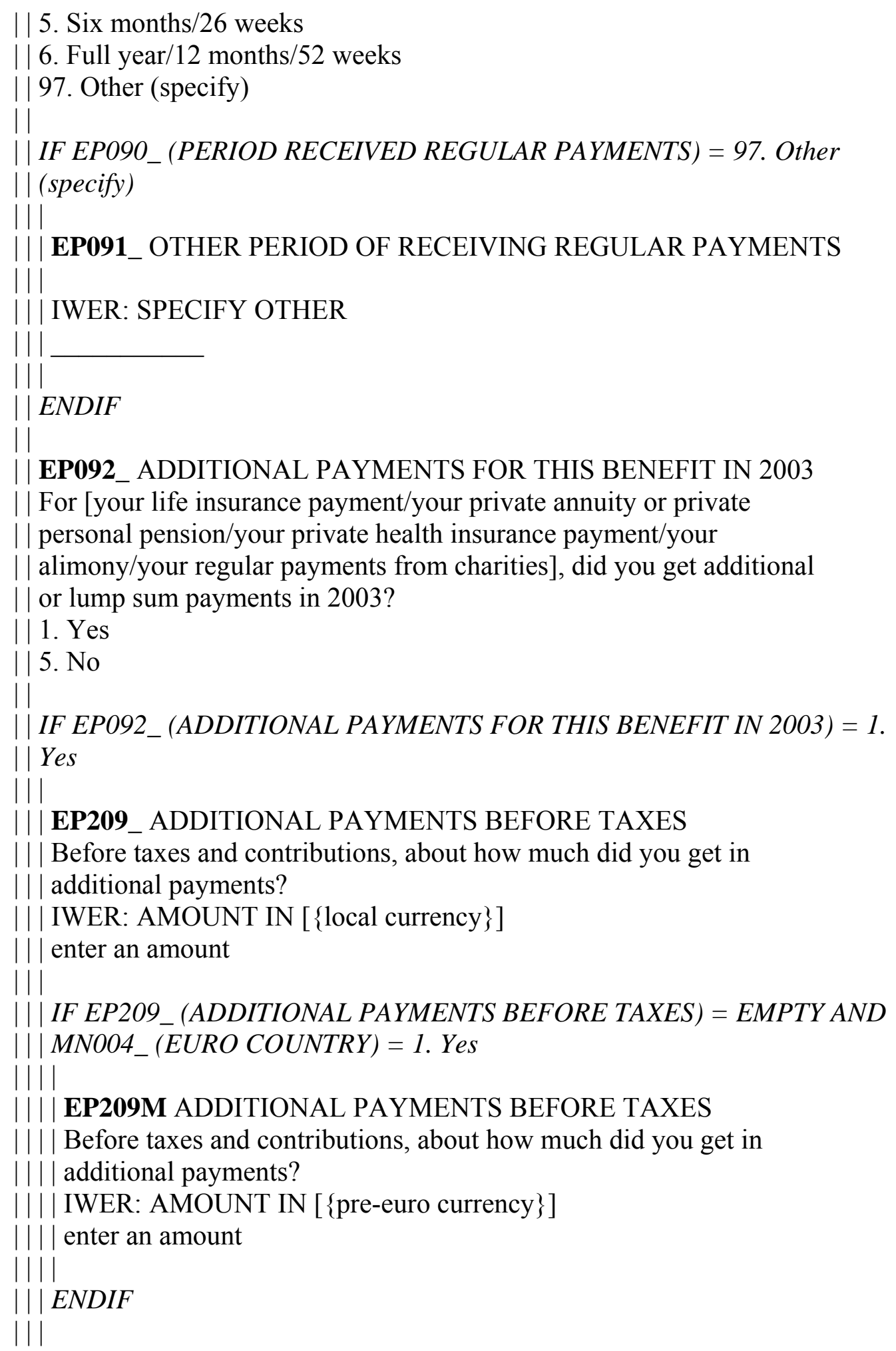




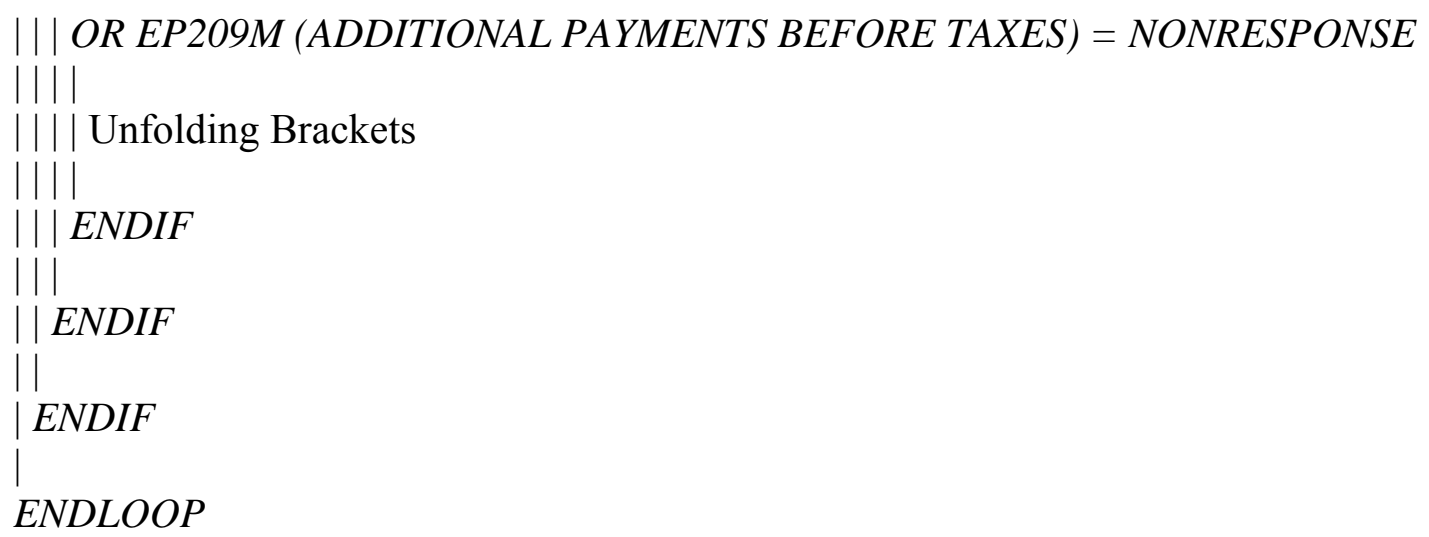

\section{EP097_PENSION CLAIMS}

Now we are talking about future pension entitlements. Please look at card 26. Are you entitled to at least one pension listed on this card which you do not receive currently?

1. Yes

5. No

IF EP097_(PENSION CLAIMS) $=1$. Yes

|

| EP098_TYPE OF PENSION YOU ARE ENTITLED TO

Which type or types of pension are you entitled to?

| IWER: CODE ALL THAT APPLY

1. Public old age pension

2. Public early retirement or pre-retirement pension

3. Public disability insurance; sickness/invalidity/incapacity pension

4. Private (occupational) old age pension

5. Private (occupational) early retirement pension

96. None of these

|

CHECK: You cannot select 'None of the above' together with any other answer.

Please change your answer.

| LOOP cnt = 1 TO 9

|

|| IF cnt IN EP098_(TYPE OF PENSION YOU ARE ENTITLED TO)

|l|

| | | EP099_PENSION WITH/WITHOUT HEALTH INSURANCE

| | | Does [the public old age pension/the public early retirement or

| | | pre-retirement pension/the public disability insurance;

| || sickness/invalidity/incapacity pension/the private (occupational) old

| | age pension/the private (occupational) early retirement

| | pension] include also health

| | insurance?

| || 1. Pension only

||| 2. Pension and health insurance 


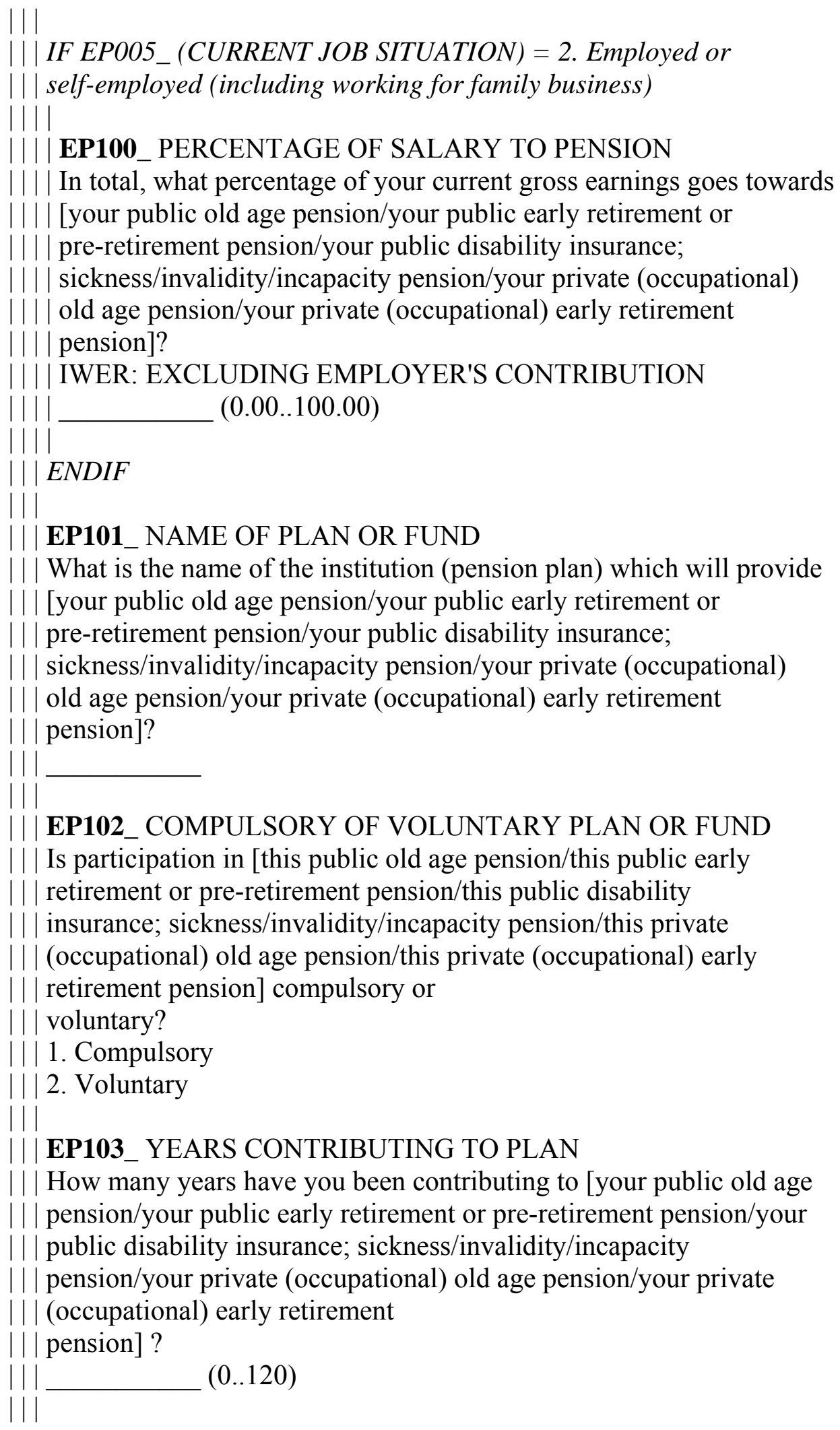




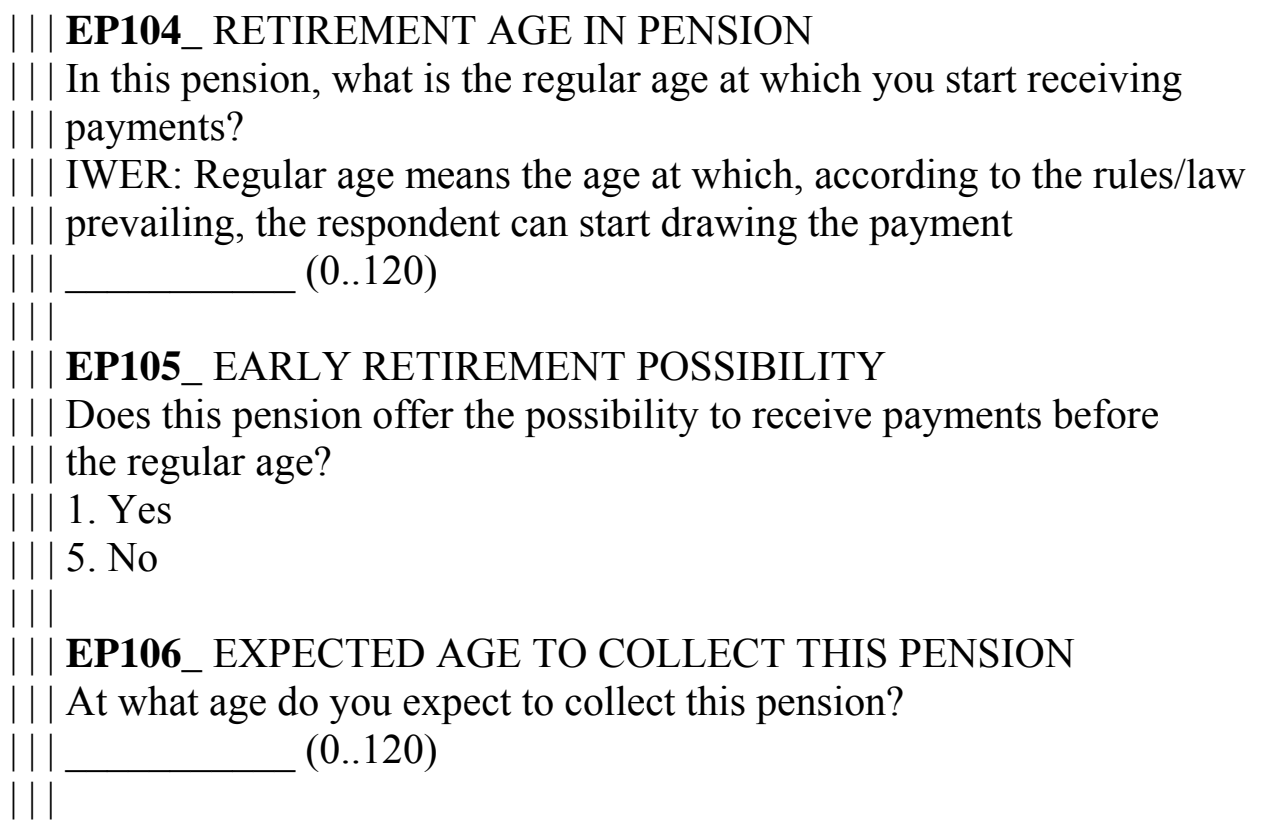

CHECK: Expected age should be higher than or equal to current age.

| | | EP107_EXPECT LUMP SUM PAYMENT WITH THIS PENSION

| | | Do you expect to receive a lump sum (one off) payment with this

| || pension?

|||1. Yes

|| 5. No

||

| || IF EP107_(EXPECT LUMP SUM PAYMENT WITH THIS PENSION) $=1$.

| ||Yes

| | |

| | | | EP108_AMOUNT LUMP SUM PAYMENT AT RETIREMENT

| | | | How much do you expect to receive as a lump sum payment when you

| | | collect this pension?

| | | IWER: AMOUNT IN [\{local currency $\}$ ]

| | | enter an amount

| ||

| | | IF EP108_(AMOUNT LUMP SUM PAYMENT AT RETIREMENT) = EMPTY

| | | AND MN004_(EURO COUNTRY) $=1$. Yes

\|\|

| | | | | EP108M AMOUNT LUMP SUM PAYMENT AT RETIREMENT

|| | | How much do you expect to receive as a lump sum payment when you

| | | | collect this pension?

| | | | IWER: AMOUNT IN [\{pre-euro currency\}]

|| | | enter an amount

|| ||

| | | ENDIF

|l| 
CHECK: Please enter a value.

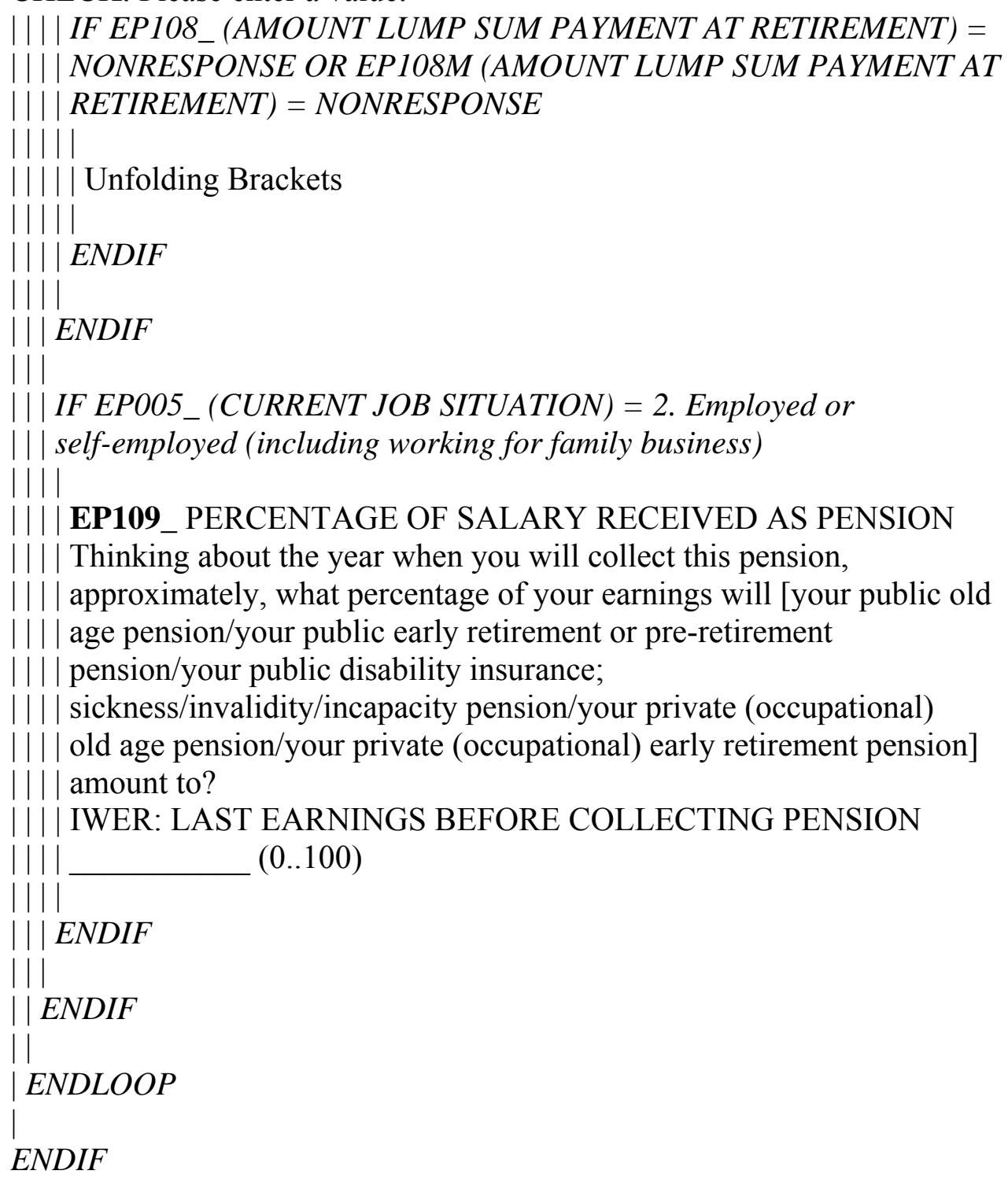




\section{APPENDix C.1. FlowChaRT OF EP MOdUle: LABOR ForCE PARTICIPATION}

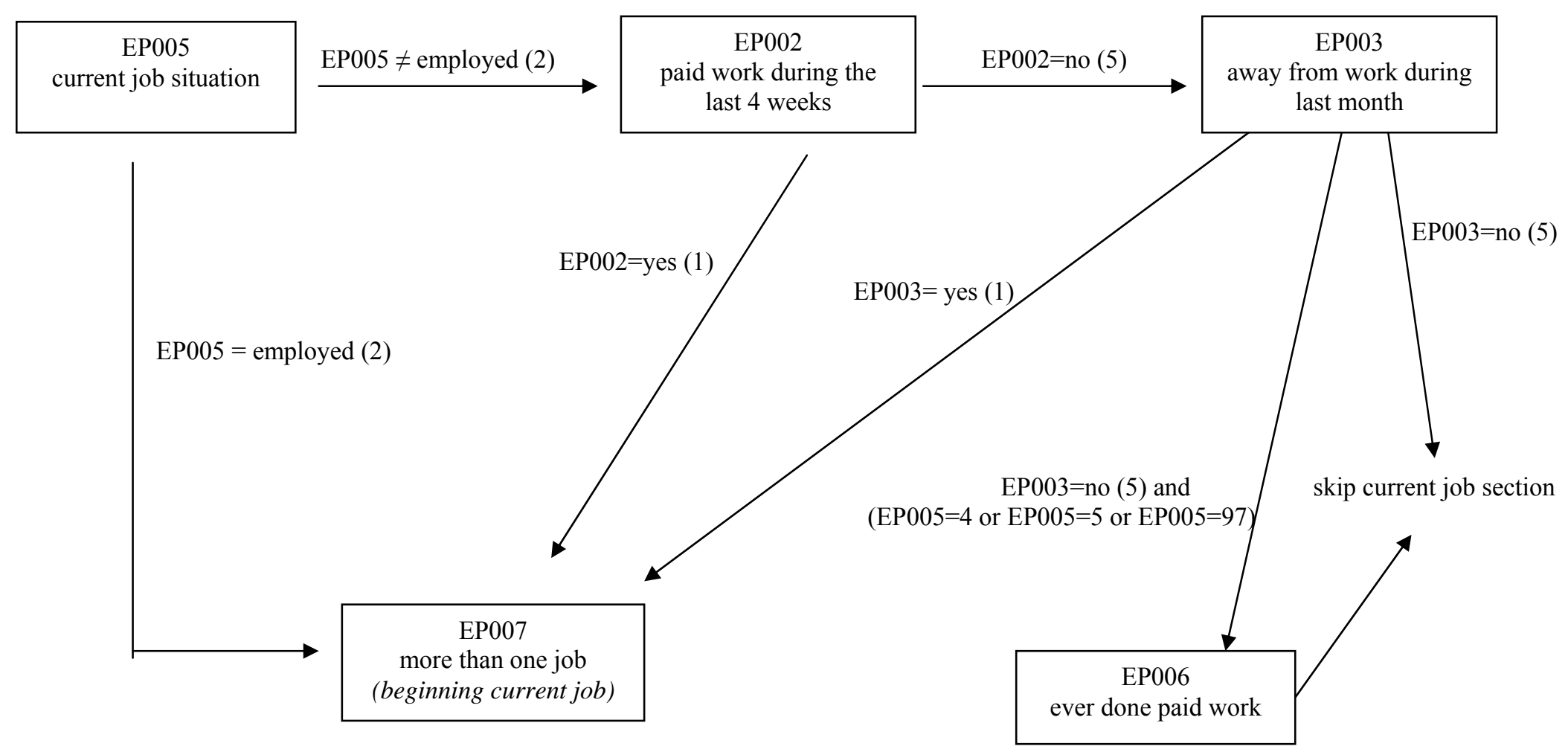




\section{APPENDiX C.2. FlowChART OF EP MOdUle: CURRENT (MAIN) ${ }^{31}$ JOB SITUATION}

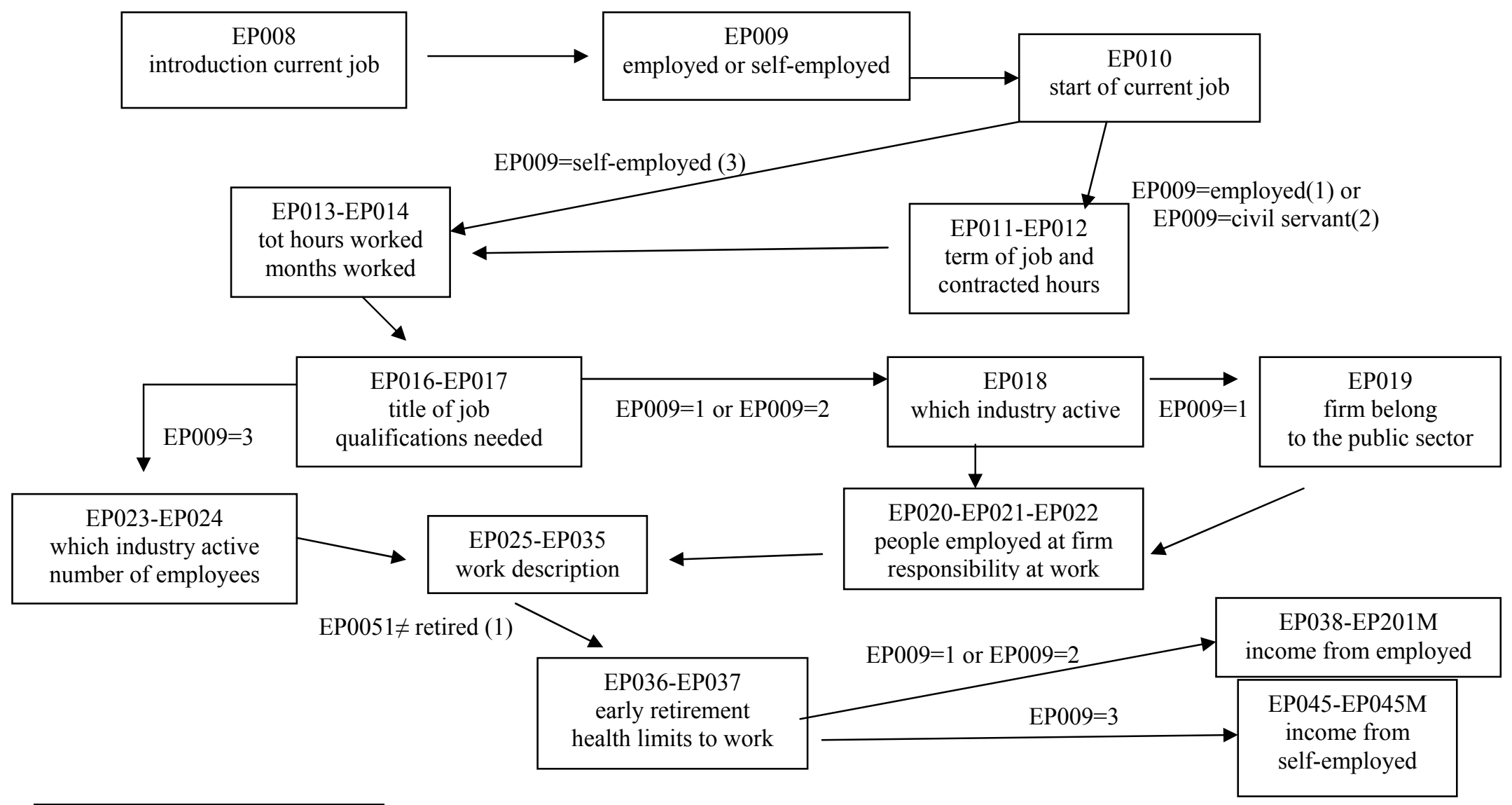

${ }^{31}$ The questions about work description (EP025-EP035) are asked only for main job. 


\section{APPENDix C.3. Flowchart Of EP Module: Past Job Situation}

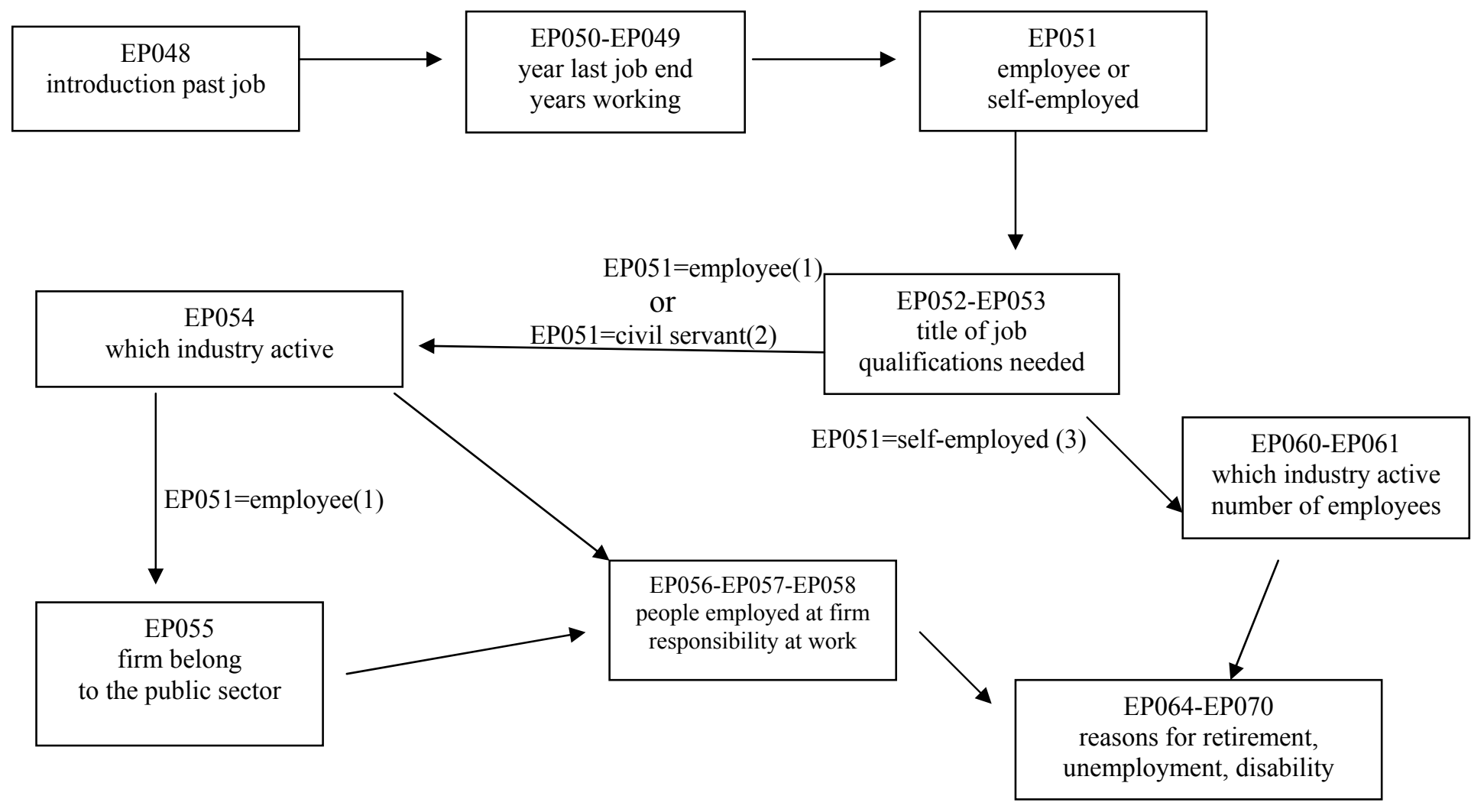


APPENDIX C.4. FlOWCHART OF EP MOdULE: LAST YEAR INCOME AND FUTURE BENEFITS ENTITLEMENTS

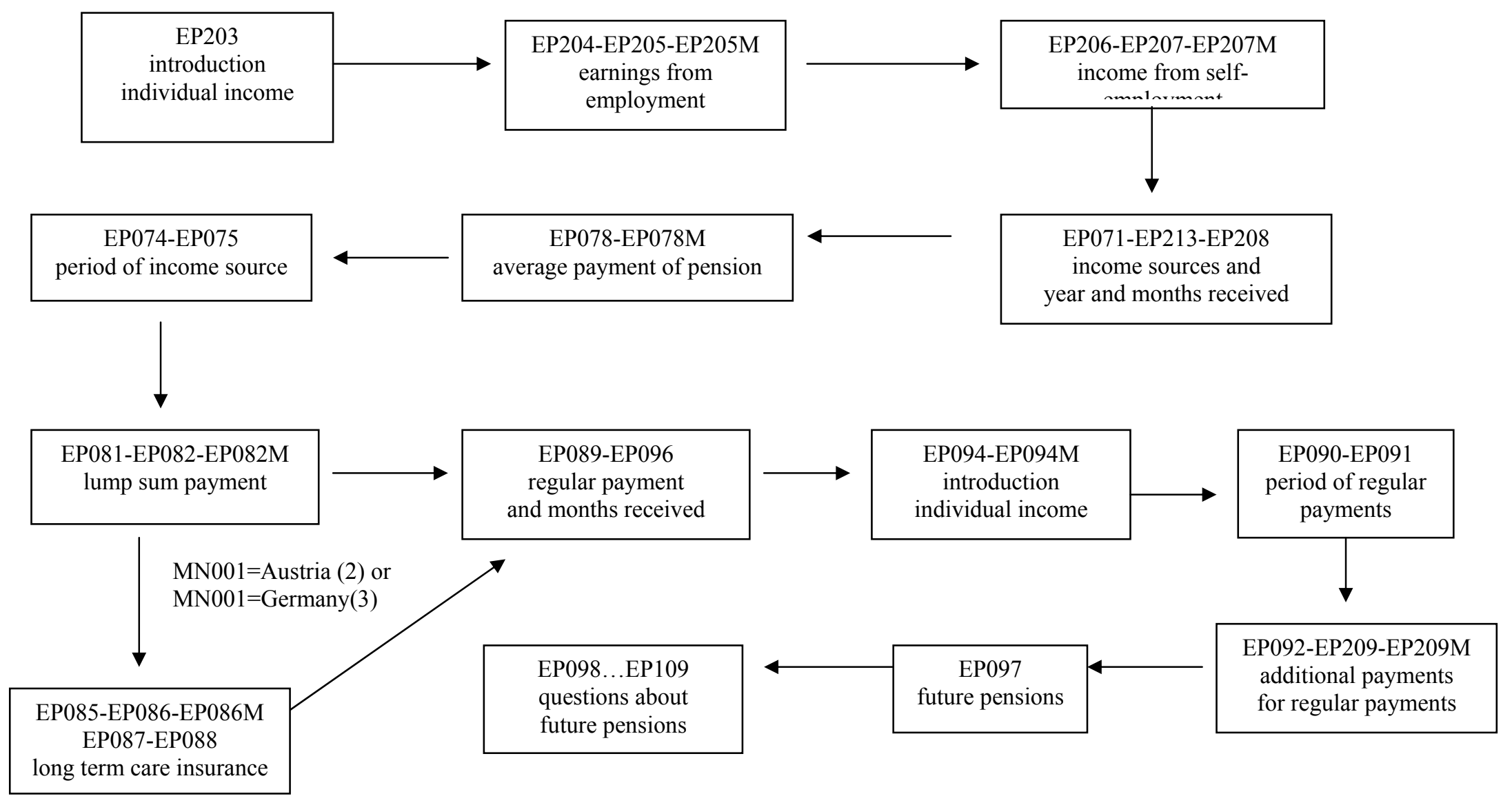


APPENDIX D.1. COUNTRY-SPECIFIC DEVIATIONS: QUESTION EP071 (INCOME SOURCES FROM BENEFITS IN THE LAST YEAR)

\begin{tabular}{|c|c|c|c|c|c|c|c|c|c|c|}
\hline GENERIC & AT & $\mathrm{CH}$ & $\mathrm{DE}$ & DK & ES & FR & GR & IT & NL & SE \\
\hline 1. Public old age pension & & & & & & & & includes social pension & & \\
\hline $\begin{array}{l}\text { 2. Public early retirement or pre- } \\
\text { retirement pension }\end{array}$ & $\begin{array}{c}\text { "pre } \\
\text { retirement" } \\
\text { not included }\end{array}$ & & & $\begin{array}{c}\text { early retirement } \\
\text { benefit/pension; } \\
\text { long term unemployment }\end{array}$ & & $\begin{array}{l}\text { only pre } \\
\text { retirement }\end{array}$ & & & & $\begin{array}{l}\text { disability insurance } \\
\text { benefits }\end{array}$ \\
\hline 3. Public disability insurance & & & & $\begin{array}{l}\text { sickness benefit } \\
\text { (temporary benefits for } \\
\text { people who are sick) }\end{array}$ & & & & $\begin{array}{c}\text { includes } \\
\text { "assegno di } \\
\text { accompagnamento" }\end{array}$ & & survivor benefits \\
\hline $\begin{array}{l}\text { 4. Public unemployment benefit } \\
\text { or insurance }\end{array}$ & & & & $\begin{array}{l}\text { insurance means: } \\
\text { social assistance }\end{array}$ & & $\begin{array}{c}\text { unemployment } \\
\text { benefits }\end{array}$ & & & & $\begin{array}{c}\text { occupational pensions for } \\
\text { blue-collar in the private } \\
\text { sector }\end{array}$ \\
\hline $\begin{array}{l}\text { 5. Public survivor pension from } \\
\text { your spouse or partner }\end{array}$ & & & & & & $\begin{array}{l}\text { survivor pension } \\
\text { from } \\
\text { a basic regime } \\
\end{array}$ & & & & $\begin{array}{c}\text { occupational pensions for } \\
\text { white-collar workers in } \\
\text { the private sector }\end{array}$ \\
\hline $\begin{array}{l}\text { 6. Public invalidity or incapacity } \\
\text { pension }\end{array}$ & $\begin{array}{c}\text { includes a } \\
\text { support for } \\
\text { disabled } \\
\text { people }\end{array}$ & & -. & $\begin{array}{c}\text { disability benefits } \\
\text { (people with permanently } \\
\text { reduced labour market } \\
\text { capacity) }\end{array}$ & & $\begin{array}{l}\text { public invalidity } \\
\text { pension }\end{array}$ & $\begin{array}{c}\text { benefits for poor } \\
\text { and for families } \\
\text { with more than } \\
4 \text { children } \\
\end{array}$ & & $\begin{array}{l}\text { public income support } \\
\text { incapacity, incapacity } \\
\text { supplement }\end{array}$ & $\begin{array}{l}\text { occupational pensions for } \\
\text { government workers }\end{array}$ \\
\hline 7. War pension & & & & & & & & & & $\begin{array}{c}\text { occupational pension for } \\
\text { municipal and local } \\
\text { government workers }\end{array}$ \\
\hline $\begin{array}{l}\text { 8. Private (occupational) old age } \\
\text { pension }\end{array}$ & & & & & & $\begin{array}{c}\text { one or several } \\
\text { complementary } \\
\text { old age pensions }\end{array}$ & & & & $\begin{array}{c}\text { other occupational } \\
\text { pension benefits }\end{array}$ \\
\hline $\begin{array}{l}\text { 9. Private (occupational) early } \\
\text { retirement pension }\end{array}$ & & & -. & $\begin{array}{l}\text { payments before the } \\
\text { normal retirement age }\end{array}$ & & $\begin{array}{l}\text { pre-retirement } \\
\text { pension paid by } \\
\text { the employer }\end{array}$ & & & & $\begin{array}{l}\text { unemployment insurance } \\
\text { benefits }\end{array}$ \\
\hline $\begin{array}{l}\text { 10. Private (occupational) } \\
\text { disability or invalidity insurance }\end{array}$ & & & & & & $\begin{array}{l}\text { a invalidity benefit } \\
\text { paid by the } \\
\text { employer }\end{array}$ & & & & sickness benefits \\
\hline $\begin{array}{l}\text { 11. Private (occupational) } \\
\text { survivor pension from your } \\
\text { spouse or partner's job }\end{array}$ & & & & & & $\begin{array}{c}\text { a survivor pension } \\
\text { from a } \\
\text { complementary } \\
\text { regime }\end{array}$ & & & & -- \\
\hline
\end{tabular}


APPENDIX D.2. COUNTRY-SPECIFIC DEVIATIONS: QUESTION EP098 (INCOME SOURCES FROM FUTURE BENEFITS)

\begin{tabular}{|c|c|c|c|c|c|c|c|c|c|c|}
\hline GENERIC & $\mathrm{AT}$ & $\mathrm{CH}$ & $\mathrm{DE}$ & DK & ES & FR & GR & IT & $\mathrm{NL}$ & SE \\
\hline $\begin{array}{l}\text { 1. Public old age } \\
\text { pension }\end{array}$ & & & & & & & & & - - & \\
\hline $\begin{array}{l}\text { 2. Public early } \\
\text { retirement or pre- } \\
\text { retirement pension }\end{array}$ & & & & & - - & & & - - & & $\begin{array}{c}\text { occupational pension } \\
\text { for blue-collar } \\
\text { workers } \\
\text { in the private sector }\end{array}$ \\
\hline $\begin{array}{l}\text { 3. Public disability } \\
\text { insurance; } \\
\text { sickness/invalidity/incap } \\
\text { acity pension }\end{array}$ & & & & & & & & & & $\begin{array}{c}\text { occupational pension } \\
\text { for white-collar } \\
\text { workers } \\
\text { in the private sector }\end{array}$ \\
\hline $\begin{array}{l}\text { 4. Private (occupational) } \\
\text { old age pension }\end{array}$ & & & & & & $\begin{array}{l}\text { complementary } \\
\text { pension }\end{array}$ & & & & $\begin{array}{l}\text { occupational pensions } \\
\text { for government } \\
\text { workers }\end{array}$ \\
\hline $\begin{array}{l}\text { 5. Private (occupational) } \\
\text { early retirement pension }\end{array}$ & & & -- & & - & & & - - & & $\begin{array}{c}\text { occupational pensions } \\
\text { for municipal and } \\
\text { local government } \\
\text { workers }\end{array}$ \\
\hline 6. Additional category & -- & $\begin{array}{c}\text { "3e pilier", } \\
\text { an individual, private, non-occupational } \\
\text { pension scheme }\end{array}$ & -- & -- & -- & -- & -- & -- & - - & $\begin{array}{l}\text { other occupational } \\
\text { pension }\end{array}$ \\
\hline 7. Additional category & -- & -- & -- & - & -- & -- & -- & -- & -- & private pension \\
\hline
\end{tabular}


Working Papers

Department of Economics

$\mathrm{Ca}$ ' Foscari University of Venice
No. $42 / \mathrm{WP} / 2006$ No. $42 / \mathrm{WP} / 2006$
ISSN 1827-336X 